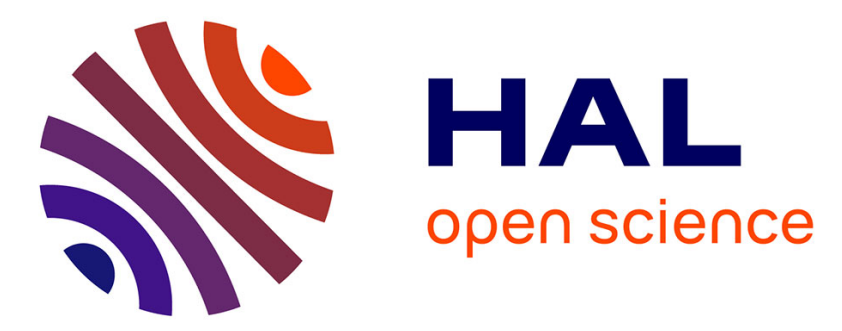

\title{
Development of a thin-film solar photobioreactor with high biomass volumetric productivity (AlgoFilm ) based on process intensification principles
}

\author{
Jeremy Pruvost, A Le Borgne, A Artu, J Legrand
}

\section{- To cite this version:}

Jeremy Pruvost, A Le Borgne, A Artu, J Legrand. Development of a thin-film solar photobioreactor with high biomass volumetric productivity (AlgoFilm ) based on process intensification principles. Algal Research - Biomass, Biofuels and Bioproducts, 2017, 21, pp.120 - 137. 10.1016/j.algal.2016.10.012 . hal-01527176

\author{
HAL Id: hal-01527176 \\ https://hal.science/hal-01527176
}

Submitted on 21 Apr 2020

HAL is a multi-disciplinary open access archive for the deposit and dissemination of scientific research documents, whether they are published or not. The documents may come from teaching and research institutions in France or abroad, or from public or private research centers.
L'archive ouverte pluridisciplinaire HAL, est destinée au dépôt et à la diffusion de documents scientifiques de niveau recherche, publiés ou non, émanant des établissements d'enseignement et de recherche français ou étrangers, des laboratoires publics ou privés. 


\title{
Development of a thin-film solar photobioreactor with high biomass volumetric productivity (AlgoFilm@) based on process intensification principles
}

\author{
J. Pruvost ${ }^{\mathrm{a}, *}$, F. Le Borgne ${ }^{\mathrm{b}}$, A. Artu ${ }^{\mathrm{a}, \mathrm{b}}$, J. Legrand ${ }^{\mathrm{a}}$ \\ a GEPEA, Université de Nantes, CNRS, UMR6144, Boulevard de l'Université, CRTT - BP 406, 44602 Saint-Nazaire Cedex, France \\ ${ }^{\mathrm{b}}$ Algosource Technologies, Boulevard de l'Université, CRTT - BP 406, 44602 Saint-Nazaire Cedex, France
}

\begin{abstract}
A B S T R A C T
This work presents the rational development up to its final characterization and validation of an intensified solar photobioreactor (PBR) for microalgal production, AlgoFilm@. Our aim was to achieve very high volumetric performance for phototrophic conditions, in the range of that found in fermentation processes.

The overall design procedure was underpinned by robust engineering rules derived from knowledge models developed for PBR in-depth modeling. This approach was used to pinpoint the main engineering parameters governing PBR kinetic performance. It introduces generic principles of PBR performance enhancement for the setting-up of culture systems combining high volumetric and areal productivities. These principles were then applied to the design of a solar culture system, integrating the attendant constraints. The result was the AlgoFilm@ PBR, based on the falling-film principle, which enables very thin culture depth (around $1.5-2 \mathrm{~mm}$ ) and provides a high specific illuminated surface area (around $500 \mathrm{~m}^{2} \cdot \mathrm{m}^{-3}$, corresponding to $2.1 \mathrm{~L} / \mathrm{m}^{2}$ illuminated surface). A complete experimental characterization was then conducted to (i) determine operating conditions for the setting of optimal parameters governing AlgoFilm@ PBR performance, such as depth of the falling film, and (ii) ensure that no limitation other than light occurred, a mandatory condition to control the system and ensure high biomass productivities.

AlgoFilm@ PBR performance was characterized by Chlorella vulgaris culture. Batch, continuous and semicontinuous cultures were run, and typical irradiation conditions of a year's operation in Nantes (France) were applied using a LED panel to simulate constant, and then fully-controlled day/night cycles. Our results demonstrate the high performance of the AlgoFilm@ PBR, with volumetric productivities very close to those expected from the prior theoretical design. The best measured productivity was $5.7 \mathrm{~kg} \cdot \mathrm{m}^{-3} \cdot \mathrm{day}^{-1}\left(7.07 \mathrm{~kg} \cdot \mathrm{m}^{-3} \cdot \mathrm{day}^{-1}\right.$ in constant light). This value was significantly higher than those reported in the literature, and similar to those generally found for microalgal production in heterotrophic processes.
\end{abstract}

\section{Introduction}

Despite their high industrial potential, microalgae remain an emerging new bioresource. This holds especially for applications such as biofuels and green chemistry, which imply mass-scale, cost-effective and sustainable production. Setting up efficient industrial systems for large-scale microalgal cultivation is still a hurdle, mainly because of the difficulty met in devising large-scale, efficient, robust systems that will maintain optimal growth and sunlight conversion in actual outdoor operating conditions.

Abbreviations: PAR, photosynthetically active radiation; PBR, photobioreactor; PFD, photon flux density.

* Corresponding author.

E-mail address: jeremy.pruvost@univ-nantes.fr (J. Pruvost).
Microalgal cultivation systems call on a wide range of technological solutions, from open ponds to closed intensified photobioreactors (PBRs). Benefits and limitations of each have been extensively reviewed in recent years [1-5]. Open systems are easier to scale up, and have proved over several decades to be useful industrial solutions for massscale production of microalgae. However, their low controllability limits their application to some specific robust strains, and impedes maximum performance in terms of sun-to-biomass conversion [6]. Closed PBR technology, by contrast, involves more complex and costly processes, and is difficult to scale up for mass production on large land areas. However, it provides the necessary controlled conditions to avoid external contamination, greatly increasing the number of species that can be cultivated, and it provides optimized growth conditions for the species in culture. Light-limited conditions, where light alone limits growth, can therefore be envisaged, opening up the possibility of developing biomass cultivation systems maximizing solar energy conversion into 


\section{Nomenclature}

A Local specific rate of photon absorption $\left[\mu \mathrm{mol}_{\mathrm{h} v} \mathrm{~kg}^{-1}\right.$ $\mathrm{s}^{-1}$ ]

a Volumetric interfacial exchange area $\left[\mathrm{m}^{2} \cdot \mathrm{m}^{-3}\right.$ or $\left.\mathrm{m}^{-1}\right]$

$a_{\text {light }} \quad$ Specific illuminated area for the photobioreactor $\left[\mathrm{m}^{2} \cdot \mathrm{m}^{-3}\right.$ or $\left.\mathrm{m}^{-1}\right]$

$b \quad$ Back-scattered fraction for radiation [dimensionless]

$C_{X} \quad$ Biomass concentration $\left[\mathrm{kg} \cdot \mathrm{m}^{-3}\right]$

$C_{\mathrm{L}} \quad$ Dissolved oxygen concentration $\left[\mathrm{kg} \cdot \mathrm{m}^{-3}\right]$

$D \quad$ Dilution rate $\left[\mathrm{h}^{-1}\right.$ or $\left.\mathrm{s}^{-1}\right]$

$E_{\mathrm{a}} \quad$ Mass absorption coefficient $\left[\mathrm{m}^{2} \cdot \mathrm{kg}^{-1}\right]$

$E_{\mathrm{s}} \quad$ Mass scattering coefficient $\left[\mathrm{m}^{2} \cdot \mathrm{kg}^{-1}\right]$

$f_{\mathrm{d}} \quad$ Design dark volume fraction of the photobioreactor [dimensionless]

$G \quad$ Local spherical irradiance $\left[\mu \mathrm{mol}_{\mathrm{h} v} \cdot \mathrm{s}^{-1} \cdot \mathrm{m}^{-2}\right]$

$\mathrm{J}_{2} \quad$ Local specific rate of oxygen production or consumption $\left[\mathrm{mol}_{\mathrm{O} 2} \mathrm{~kg}_{X}^{-1} \mathrm{~s}^{-1}\right.$ ]

$k_{\mathrm{L}} \quad$ mass transfer coefficient $\left[\mathrm{m} \cdot \mathrm{s}^{-1}\right]$

$k_{\mathrm{L}} a \quad$ Volumetric mass transfer coefficient $\left[\mathrm{s}^{-1}\right]$

$K$ Half saturation constant for photosynthesis $\left[\mathrm{mmol}_{\mathrm{h} v} \cdot \mathrm{s}^{-1} \cdot \mathrm{m}^{-2}\right.$ ]

$K_{\mathrm{A}}$ Half saturation constant for photosynthesis $\left[\mu \mathrm{mol}_{\mathrm{h} v} \mathrm{~kg}^{-1} \mathrm{~s}^{-1}\right.$ ]

$L_{z} \quad$ Depth of culture [m]

$M_{X} \quad$ C-molar mass for the biomass $\left[\mathrm{kg}_{X} \cdot \mathrm{mol}_{X}^{-1}\right]$

$N_{\mathrm{O}_{2}} \quad$ Oxygen mass transfer rate $\left[\mathrm{kg} \cdot \mathrm{m}^{-3} \cdot \mathrm{s}^{-1}\right]$

$P_{V} \quad$ Biomass volumetric productivity $\left[\mathrm{kg} \cdot \mathrm{m}^{-3} \cdot \mathrm{s}^{-1}\right.$ or $\mathrm{kg} \cdot \mathrm{m}^{-3} \cdot \mathrm{h}^{-1}$ ]

$P_{\mathrm{O}_{2}} \quad$ Oxygen volumetric productivity $\left[\mathrm{kg} \cdot \mathrm{m}^{-3} \cdot \mathrm{s}^{-1}\right.$ or $\mathrm{kg} \cdot \mathrm{m}^{-3} \cdot \mathrm{h}^{-1}$ ]

$q$ Photon flux density on a given area (PFD) $\left[\mathrm{mmol}_{\mathrm{h} v} \cdot \mathrm{s}^{-1} \cdot \mathrm{m}^{-2}\right.$ ]

$Q_{m} \quad$ liquid mass flow rate $\left[\mathrm{kg} \cdot \mathrm{s}^{-1}\right]$

$r_{\mathrm{X}} \quad$ Biomass volumetric growth rate $\left[\mathrm{kg} \cdot \mathrm{m}^{-3} \cdot \mathrm{s}^{-1}\right.$ or $\mathrm{kg} \cdot \mathrm{m}^{-3} \cdot \mathrm{h}^{-1}$ ]

$S_{\text {light }} \quad$ Illuminated area of the photobioreactor $\left[\mathrm{m}^{2}\right]$

$S_{\mathrm{X}} \quad$ Areal biomass productivity $\left[\mathrm{kg} \cdot \mathrm{m}^{-2} \cdot \mathrm{d}^{-1}\right]$

$t \quad$ Time [days or $\mathrm{s}$ ]

$V_{\mathrm{R}} \quad$ Photobioreactor volume $\left[\mathrm{m}^{3}\right]$

$x_{\mathrm{d}} \quad$ Diffuse fraction for incident PFD at any location [-]

$\mathrm{Y}_{\mathrm{O}_{2} / \mathrm{x}} \quad$ Specific yield of oxygen production [dimensionless]

$z \quad$ Depth of culture [m]

\section{Greek letters}

$\alpha \quad$ Linear scattering modulus [dimensionless]

$\delta \quad$ Extinction coefficient for the two-flux method $\left[\mathrm{m}^{-1}\right]$

$\lambda \quad$ Light wavelength [m]

$\mu \quad$ culture viscosity [Pa.s]

$v_{\mathrm{NADH}_{2}-\mathrm{O}_{2}}$

Stoichiometric coefficient of cofactor regeneration on the respiratory chain [dimensionless]

$v_{\mathrm{O}_{2}-X} \quad$ Stoichiometric coefficient of the oxygen production [dimensionless]

$\theta \quad$ Incident angle (defined from the outward normal of the PBR) [rad]

$\rho \quad$ culture density $\left[\mathrm{kg} \cdot \mathrm{m}^{-3}\right]$

$\rho_{\mathrm{M}} \quad$ Maximum energy yield for photon conversion [dimensionless]

$\tau_{\mathrm{p}} \quad$ Hydraulic residence time [h]

$\varphi \quad$ Inclination of the inclined surface [rad]

$\overline{\phi_{\mathrm{O}_{2}}^{\prime}} \quad$ Mean mass quantum yield for the Z-scheme of photosynthesis $\left[\mathrm{mol}_{\mathrm{O} 2} \cdot \mu \mathrm{mol}_{\mathrm{hv}}^{-1}\right.$ ]
Subscripts

dark Related to a dark zone in the photobioreactor

light Related to an illuminated zone in the photobioreactor

max Related to maximum value

opt Related to the optimal value for residence time

Other

$<X>=\frac{1}{V} \iiint X d V_{\text {_ }}$ Spatial averaging

$\bar{X}=\frac{1}{\Delta t} \int_{\Delta t} X \mathrm{~d} t_{-}$. Time averaging

biomass (or related biological compounds of interest). Given the current plant resource needs for human food, sustainable chemistry and biofuel production, this feature is clearly of great interest. However, to outperform open rustic low-cost systems, closed PBRs have to offer a significant increase in efficiency, and there is general agreement that engineering breakthroughs are still needed before suitable PBRs systems can be devised that meet the criteria for mass-scale sustainable cost-effective and efficient production of photosynthetic microorganisms.

Considerable advances in PBR engineering have been made in recent years. As a prerequisite for rational development, the primary aim has been to clarify the parameters governing PBR productivities so as to lay an engineering basis for scaling and optimization (see [7] for a detailed overview). As shown here, this long-term research effort now provides the knowledge needed to set general principles of PBR intensification. In the present study, these principles serve to design an innovative PBR, AlgoFilm $\odot$, that displays significantly higher volumetric performance than that reported in the field.

AlgoFilm@ is based on the falling-film principle. This concept has already been applied to microalgal cultivation, but only for open systems [8]. Two tilted surfaces (tilt angle $1.7 \%$, thickness of algal culture around $0.006 \mathrm{~m}$ ) were associated to create a circulation loop, with an interconnected tank for the carbon supply to the culture. The largest system, located in Trebon (Czech Republic) presented $224 \mathrm{~m}^{2}$ of illuminated surface (each tilted surface measuring $28 \mathrm{~m}$ by $4 \mathrm{~m}$ ) for a total culture volume of $2000 \mathrm{~L}$. The specific illuminated surface area of this system was around $110 \mathrm{~m}^{2} \cdot \mathrm{m}^{-3}$. A second system was located in Southern Greece ( $100 \mathrm{~m}^{2}$ of illuminated surface). Both PBRs operated in fedbatch mode, and high biomass densities of about $40 \mathrm{~kg} \cdot \mathrm{m}^{-3}$ were reached. Areal productivities achieved in summer ranged between 11 and $32 \mathrm{~g} \cdot \mathrm{m}^{-2} \cdot \mathrm{d}^{-1}$, corresponding approximately to volumetric productivities in the range $1.2-3.5 \mathrm{~kg} \cdot \mathrm{m}^{-3} \cdot \mathrm{d}^{-1}$.

This work presents the rational development up to its final characterization and validation of the AlgoFilm@ PBR. To illustrate the overall engineering approach underpinned by robust engineering rules derived from PBR modeling, the most relevant engineering parameters governing solar PBR productivity are first given. These form a basis for introducing the main principles of PBR intensification for the setting-up of systems combining high volumetric and areal productivities. This theoretical engineering background was used to design the AlgoFilm@ $\odot$ PBR. Finally, performance was assessed by cultivating Chlorella vulgaris in different operating conditions, including diurnal light cycles. Experimental results are compared with the predictions of the model used in the design step. Our findings confirm the utility of the proposed engineering approach, with a deviation of $<20 \%$ between expected and obtained productivities. PBR modeling can thus help the rational design and systematic intensification of microalgal cultivation systems.

\section{Photobioreactor engineering and scaling rules}

\subsection{Engineering rules for maximal PBR productivity prediction}

In microalgal culture, the conditions needed to obtain maximal biomass productivity are today well-established [9-11]. All cultivation conditions, such as $\mathrm{pH}$ and temperature, have to be controlled at their 
optimal value, and nutrients (minerals, dissolved carbon concentration) have to be provided in adequate amounts to avoid growth limitation. This provides "light-limited conditions". The first consequence is that controlling the incident light and its effect on the process leads to the control of the entire cultivation system performance. This corresponds to the so-called "physical limitation" in chemical engineering, when the process is limited by one parameter, control of which enables the control of the entire process. A second important consequence is that, by definition, the culture is not subject to any other limitation. Maximum biomass productivity can thus be achieved, and is determined solely by the amount of light supplied to the system, and its utilization by the culture. As a result, maximum biomass productivity will be obtained for optimal light attenuation conditions, as already demonstrated elsewhere by the authors [3,7,10-12].

Based on the above, engineering rules governing maximal PBR productivities were first published by Cornet and Dussap [13] for constant artificial illumination conditions. This approach was then extended to the case of solar use, introducing specific features such as the effect of the incident angle $\theta$ and of the diffuse-direct distribution of solar radiation on resulting conversion in the cultivation system [7]. These relations enable us to calculate maximal areal $\left(S_{X} \max \right)$ and volumetric $\left(P_{X \text { max }}\right)$ productivities for a given culture system:

$$
\begin{aligned}
\overline{S_{X \max }=} & \left(1-f_{d}\right) \rho_{\mathrm{M}} \frac{{\overline{\phi^{\prime}}}_{\mathrm{O}_{2}} M_{X}}{v_{\mathrm{O}_{2}-X}} \frac{2 \alpha}{1+\alpha}\left[\frac{\bar{x}_{d} K}{2} \ln \left[1+\frac{2 \bar{q}}{K}\right]+\left(1-\bar{x}_{d}\right)\right. \\
& \left.\overline{\cos \theta} K \ln \left[1+\frac{\bar{q}}{K \overline{\cos \theta}}\right]\right]
\end{aligned}
$$

with $\overline{P_{X \max }}=\overline{S_{X \max }} \frac{S_{\text {light }}}{V_{R}}=\overline{S_{X \max }} a_{\text {light }}$.

The parameters of Eq. (1) can be split into three groups:

- Parameters related to the cultivated species: the mean mole $\mathrm{O}_{2}$ quantum yield $\overline{\phi_{\mathrm{O}_{2}}^{\prime}}$, the C-molar mass $M_{x}$, the half saturation constant for photosynthesis $K$, the stoichiometric coefficient of the oxygen production $v_{\mathrm{O}_{2}-X}$ and the linear scattering modulus $\alpha$ related to radiative properties of the microorganism.

- Parameters related to the operating conditions: the cosine of the incident angle $\theta$ on the PBR surface $\overline{\cos \theta}$, the total collected PFD $\bar{q}$ with corresponding diffuse fraction $\bar{x}_{\mathrm{d}}$.

- Parameters related to PBR geometry: specific illuminated area $a_{\text {light }}$ given by the ratio of PBR illuminated area to total culture volume, and the design dark volume fraction $f_{\mathrm{d}}$, i.e. any volume fraction of the PBR not lit by the incident PFD.

For a given species, parameters affecting PBR productivity are the design-specific illuminated area $a_{\text {light, }}$, the design dark fraction of the reactor $f_{\mathrm{d}}$ and the ability of the PBR to collect light, as characterized by incident PFD $\bar{q}$, related cosine of the incident angle $\overline{\cos \theta}$ and diffuse fraction $\bar{x}_{d}$. We note that all these parameters are linked to the light supply. This reflects the fact that maximal performance is obtained by definition in optimal running conditions, in which light alone limits growth, assuming all other biological needs (nutrients, dissolved carbon) and operating conditions ( $\mathrm{pH}$, temperature) are controlled at optimal values [12,14,15].

When these engineering formulas are used for the design of PBRs, Eq. (1) can be simplified for convenience with regard to parameters related to PBR location or operating conditions. Ideal radiations conditions can also be assumed, with a PFD composed solely of collimated light $\left(\bar{x}_{d}=0\right)$ and at normal incidence $(\overline{\cos \theta}=1)$. This yields the simplified formulas:

$\overline{S_{X \max }}=\left(1-f_{\mathrm{d}}\right) \rho_{\mathrm{M}} \frac{\overline{\phi_{\mathrm{O}_{2}}^{\prime}} M_{X}}{v_{\mathrm{O}_{2}-X}} \frac{2 \alpha}{1+\alpha} K \ln \left[1+\frac{\bar{q}}{K}\right]$, and

$$
\overline{P_{X \max }}=a_{\text {light }}\left(1-f_{\mathrm{d}}\right) \rho_{\mathrm{M}} \frac{{\overline{\phi^{\prime}}}_{\mathrm{O}_{2}} M_{X}}{v_{\mathrm{O}_{2}-X}} \frac{2 \alpha}{1+\alpha} K \ln \left[1+\frac{\bar{q}}{K}\right]
$$

We note the practical utility of these analytic formulas, which are relatively simple considering the complex phenomena involved in microalgal cultivation processes (e.g. photosynthetic conversion and light attenuation in the culture volume). Maximal biomass productivity is highly valuable information. It can be used, for example, to scale the system as a function of operational constraints, e.g. objective of biomass production, or available algae farming resources (land area, irradiation conditions, etc.). In many cases, this information is considered sufficient for the engineer to estimate, for example, the number/size of production units and the attendant capital and operating costs (CAPEX and OPEX).

\subsection{Illustration of the influence of engineering parameters on maximal ar- eal and volumetric biomass productivities of PBRS}

The influence of the main engineering parameters on maximal productivities as predicted by Eq. (2) is illustrated in Fig. 1. Performance is
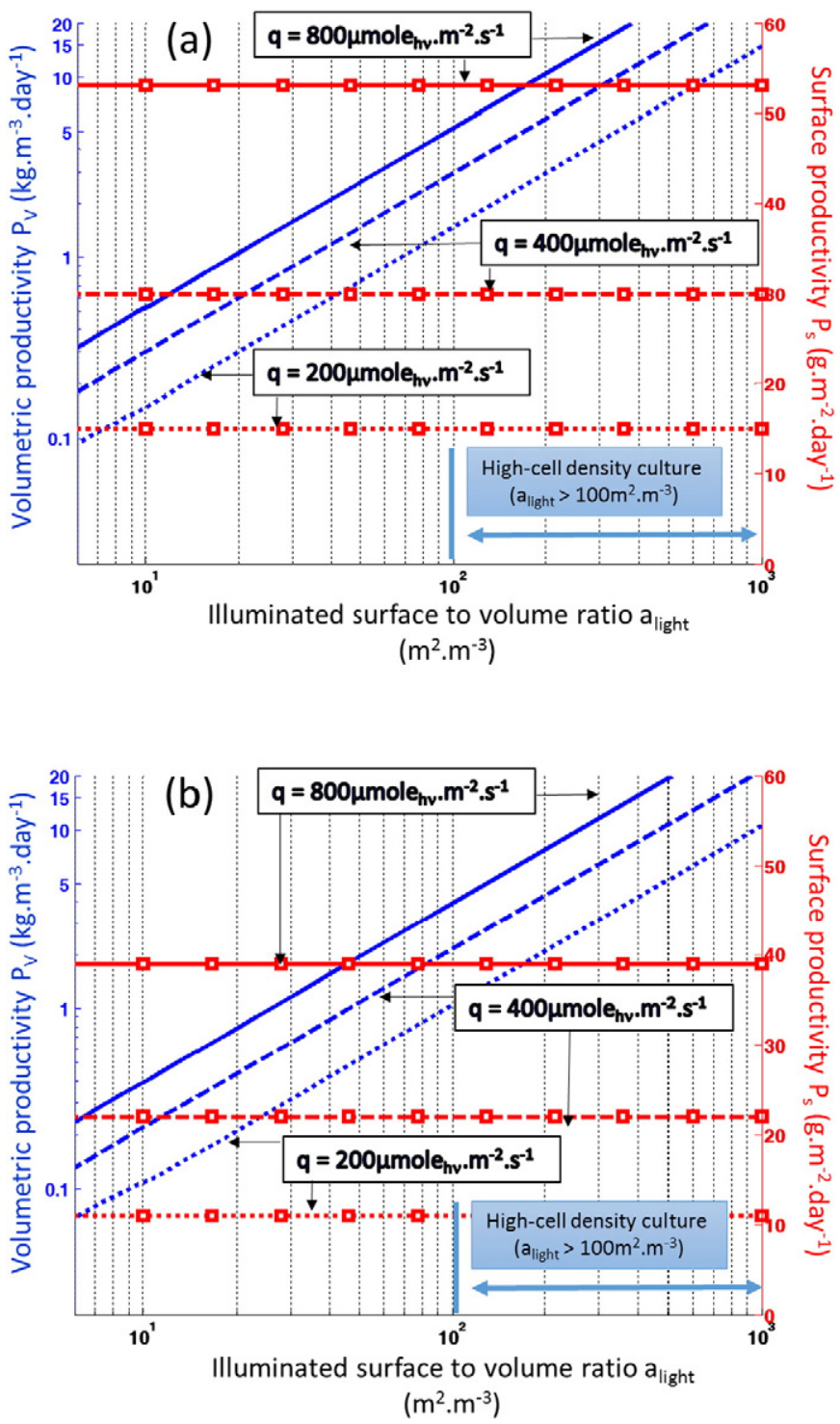

Fig. 1. Influence of PFD ( $q)$, illuminated surface to volume ratio ( $\left.\mathrm{a}_{\text {light }}\right)$ and design dark volume fraction $\left(\mathrm{f}_{\mathrm{d}}\right.$ ) on both areal (square) and volumetric (no symbol) PBR maximal productivities in the case of Chlorella vulgaris cultivation (1-a: $f_{d}=0 \% ; 1-b: f_{d}=20 \%$ ) 
given here for the case of $C$. vulgaris cultivation with parameters from Soulies et al. [16]. See also Appendix A for more details.

Fig. 1 shows that specific illuminated area $a_{\text {light }}$ strongly influences volumetric productivity. Two orders of magnitude are covered for typical values obtained in practice, i.e. ranging from around $2 \mathrm{~m}^{2} \cdot \mathrm{m}^{-3}$ (depth $0.5 \mathrm{~m}$ ) to around $100 \mathrm{~m}^{2} \cdot \mathrm{m}^{-3}$ (flat panel with depth $0.01 \mathrm{~m}$ ). However, it has no influence on areal productivity, as expected (Eq. (3)): it is well-established that when expressed per unit area and under light limitation, maximal productivity is independent of PBR depth $[17,18]$. PFD is also relevant, as it has a positive effect on both areal and volumetric productivities. In solar conditions, the PFD will be defined by the ability of the system to collect light, which will depend on PBR geometry and positioning, as shown in numerous studies [19-21]. We note that due to the progressive saturation of photosynthetic conversion (as represented by the parameter $K$, which is species-dependent), an increase in PFD received on the cultivation system will increase productivity (as shown in Fig. 1) but will also lower the thermodynamic efficiency of the process (i.e. yield of conversion of light energy into biomass). For example, increasing the PFD 4-fold (from 200 to $800 \mu \mathrm{mole}_{\mathrm{h} v} \cdot \mathrm{m}^{-2} \cdot \mathrm{s}^{-1}$ ) leads to an increase in areal productivity of 3.5. We note here that the decrease in the conversion yield of light energy into biomass argues for using the light dilution principle, i.e. inserting light sources inside the culture so as to decrease light received by the culture, and so increase its conversion yield. However, diluting light will also be at the expense of volumetric productivity, and will have to be offset to some extent by an increase in specific illuminated area. This leads to specific volumetric lighting solutions such as the DiCoFluV concept. Interested readers can refer to Cornet [15]. Here, only surface-lit systems with direct illumination will be considered (case of AlgoFilm technology).

Fig. 1 also illustrates the effect of the design dark volume fraction $f_{\mathrm{d}}$, which negatively influences both surface and volumetric productivities. Eqs. (1) and (2) predict a proportional decrease with $f_{\mathrm{d}}$ (fulfilling their purpose of proposing simplified engineering formulas for maximal performance prediction). However, in the case of microalgae presenting significant respiration activity in the dark, this leads to an additional loss of performance. The dark volume fraction is not only a nonproducing volume (as represented in Eqs. (1) and (2)), but also contributes negatively to overall PBR performance through biomass catabolism in this unlit volume. As an illustration, Fig. 1 presents the performance for a dark volume fraction of $f_{\mathrm{d}}=20 \%$, assuming a respiration activity in the dark of $\mu_{\text {dark }}=0.02 \mathrm{~h}^{-1}$ for $C$. vulgaris (see Appendix A). The decrease in maximal PBR productivities was found in the range $25-30 \%$ for $\bar{q}=800 \mu \mathrm{mole}_{\mathrm{h} v} \cdot \mathrm{m}^{-2} \cdot \mathrm{s}^{-1}$ and $\bar{q}=200 \mu \mathrm{mole}_{\mathrm{h} v} \cdot \mathrm{m}^{-2} \cdot \mathrm{s}^{-1}$ respectively, with a slight influence of the incident PFD value (no influence of $a_{\text {light }}$ was observed). We note that in practice, a dark volume may be unavoidable in the design of some microalgal cultivation units (e.g. mixing tank in the cultivation loop of a tubular system, or unlit volume of an airlift PBR).

\subsection{Application of intensification principles for the rational development of the AlgoFilm(C PBR}

The initial design purpose of the AlgoFilm@ PBR was to propose a cultivation system for solar culture that offered very high volumetric productivity. Because microalgae are often discussed as a potential alternative to traditional crops, areal productivity is a primary criterion, and volumetric productivity is generally considered as secondary. However, microalgae grow in water, making the management of culture volume crucial in any microalgal exploitation unit. The energy consumption of several processes in the exploitation chain is directly linked to the culture volume (pumping, mixing, temperature control, harvesting, etc.). Increasing volumetric productivity can thus simplify practical operation of microalgal culture, not only by reducing operational and capital costs (pumps, tanks, etc.), but also by drastically reducing energy needs for a given operation, as most of the energy requirements are related to the culture volume (culture mixing and pumping, thermal regulation, etc.).

As described by Eq. (2), volumetric productivity can be increased with appropriate engineering, following simple guidelines provided by engineering rules. For a given microalgal species, maximal areal and volumetric productivities are given by:

$\overline{S_{X \max }} \propto\left(1-f_{\mathrm{d}}\right) \ln \left[1+\frac{\bar{q}}{K}\right]$

and $\overline{P_{X \max }}=a_{\text {light }} \overline{S_{X \max }}$.

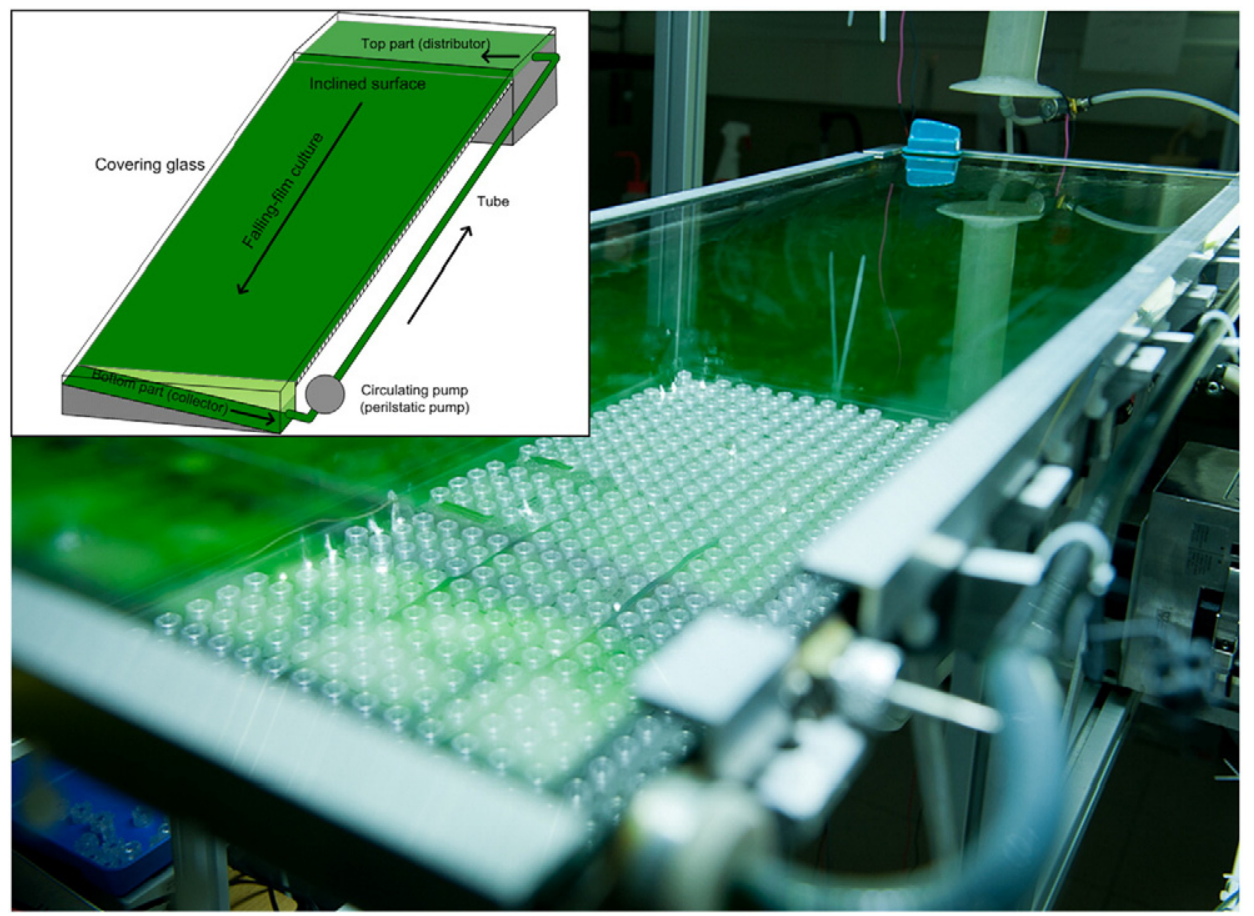

Fig. 2. AlgoFilm@ photobioreactor 
These equations show the main relevant engineering parameters affecting PBR productivity, namely specific illuminated area $a_{\text {light }}$, dark fraction $f_{\underline{\mathrm{d}}}$, and light collected $\bar{q}$. To maximize PBR performance, the design dark fraction $f_{\mathrm{d}}$ in a cultivation system, which corresponds to an unlit part of the reactor, and affects both areal and volumetric productivities, should ideally be near nil $\left(f_{\mathrm{d}} \approx 0\right)$. However, as explained previously, this is not always possible owing to practical constraints. This is the case for the AlgoFilm@ PBR (see later). Regarding $a_{\text {light }}$ and $\bar{q}$, areal productivity depends only on the PFD (i.e. $\bar{q}$ ) and volumetric productivity (or biomass concentration, the two being linked) is increased by increasing the specific illuminated area (or decreasing the culture depth, i.e. $a_{\text {light }}=S_{\text {light }} / V_{R}=1 /$ L for a flat panel) and PFD (these relations are also shown in Fig. 1). The specific illuminated surface $a_{\text {light }}$ is set by the PBR design. The utility of working with a thin culture is highlighted here. Reducing culture depth below $0.01 \mathrm{~m}$ leads to $a_{\text {light }}$ values higher than $100 \mathrm{~m}^{2} \cdot \mathrm{m}^{-3}$, compared with usually obtained values of around $20 \mathrm{~m}^{2} \cdot \mathrm{m}^{-3}$ for a PBR of depth $0.05 \mathrm{~m}$, and $0.3 \mathrm{~m}^{2} \cdot \mathrm{m}^{-3}$ for a raceway of depth $0.3 \mathrm{~m}$. There is thus a direct effect on volumetric productivity (Eq. (3) indicates a proportionality), allowing high cell density culture $\left(C_{x}>10 \mathrm{~kg} \cdot \mathrm{m}^{-3}\right)$. We also note that increasing the PFD will lead to a further increase (but with a decrease in thermodynamic yield of photosynthetic conversion, as previously discussed). Finally, as areal productivity is independent of the specific illuminated area (Eq. (2)), we note a particular feature of PBR technology intensification, namely the possibility of markedly increasing volumetric productivity, while maintaining areal productivity. This was the basis for the design of the AlgoFilm@ PBR, which aims to offer very high volumetric productivity at the current limit of performance allowed in this regard, while keeping maximal conversion of incoming light as permitted by the direct illumination principle (surface-lit system, without light dilution). We note that as explained previously, this intensification through the optimization of the PBR design has to be combined with a systematic optimization of operating and growth parameters, so as to ensure in particular that the microalgal growth will be limited only by light ("light-limited" growth conditions). Any limitation other than light-limitation would impair PBR performance, and some of the benefit of the intensified PBR design would be lost.

\section{Materials and methods}

\subsection{Experimental set-up}

\subsubsection{AlgoFilm photobioreactor}

So as to generate the thin-film culture necessary to obtain high values of specific illuminated area and volumetric productivities, the AlgoFilm@ PBR technology is based on the setting-up of microalgal culture using a falling-film principle. The culture broth is injected at the top of a tilted surface, flows down it, is collected, pumped back up through a tube and re-injected at the top, so forming a closed loop (Fig. 2). A glass plate is placed over the tilted surface, giving a fully closed geometry. A gas headspace is thus created between the glass and the falling film. We note that as the microalgal suspension is not in contact with the glass, the risk of biofilm formation on the optically transparent surface is avoided.

A peristaltic pump is used to circulate the culture with low shear stress. Air is injected continuously into the PBR headspace. Because air is not used here to circulate algae (unlike in airlift systems), a small flow rate was applied solely to renew the gas phase and avoid oxygen over-accumulation. This also limited $\mathrm{CO}_{2}$ degassing from the cultivation system. $\mathrm{CO}_{2}$ injection was controlled by $\mathrm{pH}$ measurement and was added to air injection (see next section for details).

\subsubsection{Description of the experimental set-up}

This study describes the first AlgoFilm@ prototype, in the form of a small-size PBR equipped for indoor lab-scale experiments for initial validation in a fully-controlled environment (Fig. 2). The total volume (liquid phase) of the cultivation system ranged between 0.6 and $0.7 \mathrm{~L}$ depending on operating conditions (see Eq. (4)). This total volume included a constant volume of $0.18 \mathrm{~L}$ for culture recirculation to the top of the tilted surface. Because a peristaltic pump was used for this purpose, a part of the culture volume was always unlit. This volume can usually be neglected. However, given the AlgoFilm@ concept, which involves low total culture volume, the ensuing dark fraction was around $f_{\mathrm{d}}=20 \%$. The illuminated area of the PBR being $0.3 \mathrm{~m}^{2}$, the design resulted in a culture system with an average specific illuminated area ( $a_{\text {light }}$ ) ranging from 400 to $600 \mathrm{~m}^{2} \cdot \mathrm{m}^{-3}$, depending on the culture volume (see Eq. (4)). The PBR was made of transparent material, except for the rear side, made of stainless steel (type 316L).

For indoor experiments, the PBR was illuminated by a specially designed panel of light-emitting diodes (LED P4 cool white, Seoul SemiConductor, South Korea). This LED panel was built to light the PBR surface evenly, with PFD variation controlled by voltage adjustment using a Labview Virtual Instrument (Labview 7.1, National Instruments, Texas, USA). The LED panel (collimated light source) was placed horizontally above the PBR (normal incidence). Any day-night cycles in the range of $0-1500 \mu$ mole $_{h v} \cdot \mathrm{m}^{-2} \cdot \mathrm{s}^{-1}$ could be simulated. The PFD was measured using a plane cosine quantum sensor (LI-1400, LI-COR Biosciences, USA), which measures photosynthetically active radiation (PAR) in the $400-700 \mathrm{~nm}$ waveband received in a $2 \pi$ solid angle. The mean PFD received on the PBR front face was determined by averaging 40 different measurement points (i.e. $\bar{q}$ in Eq. (2)). Light attenuation across the optical surface was taken into consideration in the models.

Sterile air was injected continuously into the PBR headspace at a flow rate of $500 \mathrm{~mL} / \mathrm{min}$. The $\mathrm{pH}$ and temperature were controlled by a $\mathrm{pH} /$ temperature probe (sensor SG 3253, Mettler Toledo, USA) monitored by the acquisition software LabVIEW. When the $\mathrm{pH}$ was higher than the set point, $\mathrm{CO}_{2}$ was injected by activating a solenoid valve. The culture medium temperature was regulated by automatic activation of an air blower fixed on the rear side.

The PBR was operated in batch, continuous and semi-continuous modes. In the continuous and semi-continuous modes, a harvesting volume ranging from $25 \%$ to $35 \%$ of the total volume per day was applied, correspond to a residence time $\tau_{\mathrm{p}}$ of $66 \mathrm{~h}$ to $100 \mathrm{~h}$. In constant light, continuous harvesting was applied (i.e. constant dilution rate of 0.010 and $0.015 \mathrm{~h}^{-1}$ ). For investigation under simulated day-night cycles, the PBR was operated in semi-continuous mode with harvesting at the same time in the day-night cycle (i.e. $17 \mathrm{~h}$ ).

\subsubsection{Definition of irradiation (PFD) conditions}

Various irradiation conditions were simulated from the LED panel, corresponding to typical conditions encountered over a year's operation at a location in Nantes (France). Hourly variations of irradiation

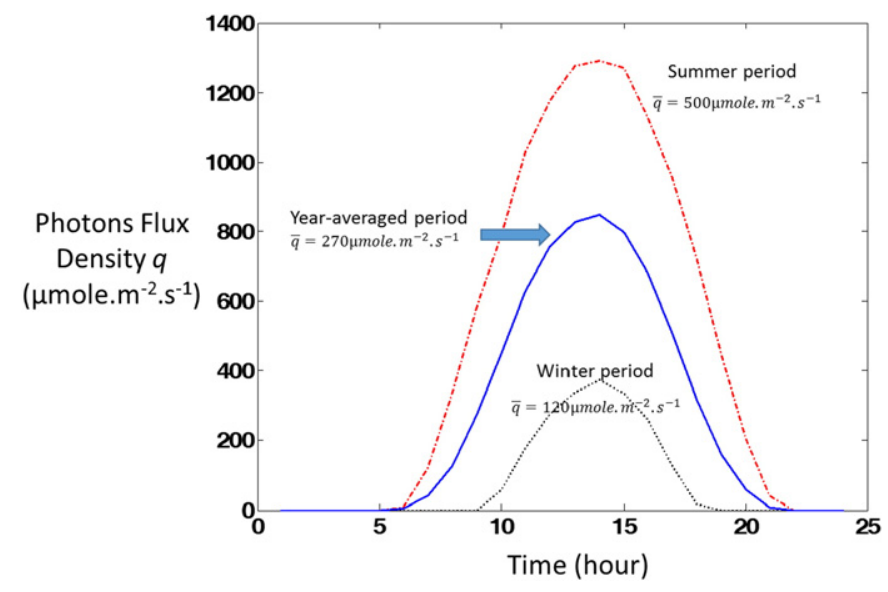

Fig. 3. Typical daytime evolutions of irradiation conditions (i.e. PFD, noted q) applied for simulated day-night cycles experiments (solide line for year-averaged period; dashdot line for summer period; dashed line for winter period). 
conditions over a year's exploitation were obtained using Meteonorm software (Meteonorm, Meteotest, Switzerland) as explained in [12]. This database was then used to define typical illumination conditions. Three values of PFD were determined, by averaging irradiation values over the full year (year-averaged irradiation condition), and over January and summer months to represent winter and summer periods respectively. These values were used for the characterization of AlgoFilm@ PBR performance in constant light. Experiments were then extended to the case of simulated day-night cycles. Day-night cycles were generated by averaging, over a given period, each daily variation obtained from the database. The same periods as for constant light were considered, namely the months of January (winter day) and July (summer day), and the full-year (year-averaged day). Corresponding day-night cycles are given in Fig. 3.

\subsection{Hydrodynamics and gas-liquid mass transfer}

\subsubsection{Liquid film thickness measurement}

The operating principle means that the film thickness $L_{z}$ on the tilted surface is of primary relevance, as it determines the specific illuminated surface $a_{\text {light. }}$ In a laminar regime, the film thickness on an inclined plane obeys the following relation, which highlights the influence of both culture flow rate and tilt angle on resulting film thickness [22]:

$L_{z}=\left(\frac{3 \cdot \mu \cdot Q_{\mathrm{m}}}{\rho^{2} \cdot g \cdot l \cdot o s \beta}\right)^{1 / 3}$

with $\beta=90-\varphi, \varphi$ being the inclination angle of the inclined plane, $\mu$ and $\rho$ the culture viscosity and density respectively, $l$ the plane width, and $Q_{\mathrm{m}}$ the liquid mass flow rate.

Eq. (4) is valid for ideal conditions (laminar regime, undisturbed free surface, etc.). Other relations are available in the literature, as film thickness can be modified in practice by numerous parameters (small variations in the flow rate, flow distribution at the top of the slope, disturbance by the gas phase, uneven supporting surface, etc.). To check the applicability of this equation in our case, culture thickness in the falling film was measured for various flow rates and surface tilt angles.

Culture thickness was measured using the needle contact method. According to Hewitt [23], the needle contact is one of the most popular methods used for measuring liquid film thickness. It consists in measuring the displacement of the needle tip between the top of the slope and the liquid film surface. The main limitation of this method is possible hysteresis during the contact between the needle and the film surface. However, this method was retained (i) because the rear side of the reactor was made of stainless steel, and so techniques based on light absorption or capacitance (or resistance) were inapplicable [24-28], and (ii) because the technique had to be mobile to measure the film thickness over the entire tilted surface; techniques requiring highly accurate alignments, such as optical fibers [29-31] or fluorescent techniques $[25,32,33]$ were therefore difficult to apply. For each condition, 15 measurements were made over the whole tilted surface to analyze film evenness.

\subsubsection{Gas-liquid mass transfer measurement}

Achieving maximal productivities in PBRs implies avoiding growth limitation by factors other than light alone. In particular, this means ensuring a sufficient supply of inorganic carbon, and preventing overaccumulation of oxygen, which could impair photosynthetic growth. Gas-liquid mass transfer in the cultivation system is thus relevant, especially in the case of high biomass productivity, when higher mass transfer performance levels are reached than in normal conditions of use. To examine this variable, gas-liquid mass transfer was measured using a de-oxygenation/re-oxygenation method to determine volumetric mass transfer coefficients $\left(k_{L} a\right)$. It consists in removing dissolved oxygen from the liquid phase by injecting gaseous nitrogen $\left(\mathrm{N}_{2}\right)$, and then monitoring the increase in dissolved oxygen concentration on switching back to air injection.

During the re-oxygenation phase, mass balance on dissolved oxygen yields the following equation:

$\mathrm{N}_{\mathrm{O}_{2}}=\frac{d C_{L}}{d t}=k_{L} a \cdot\left(C_{L}{ }^{*}-C_{L}\right)$

with $\mathrm{N}_{\mathrm{O}_{2}}$ the oxygen mass transfer rate, $C_{L}$ the dissolved oxygen concentration, and $C_{L}^{*}$ the dissolved oxygen concentration at equilibrium with the gas phase. By integrating this equation, assuming time-constant conditions of mass transfer (i.e. constant $k_{\mathrm{L}}$ a over the experiment), the following equation is obtained, which allows the volumetric mass

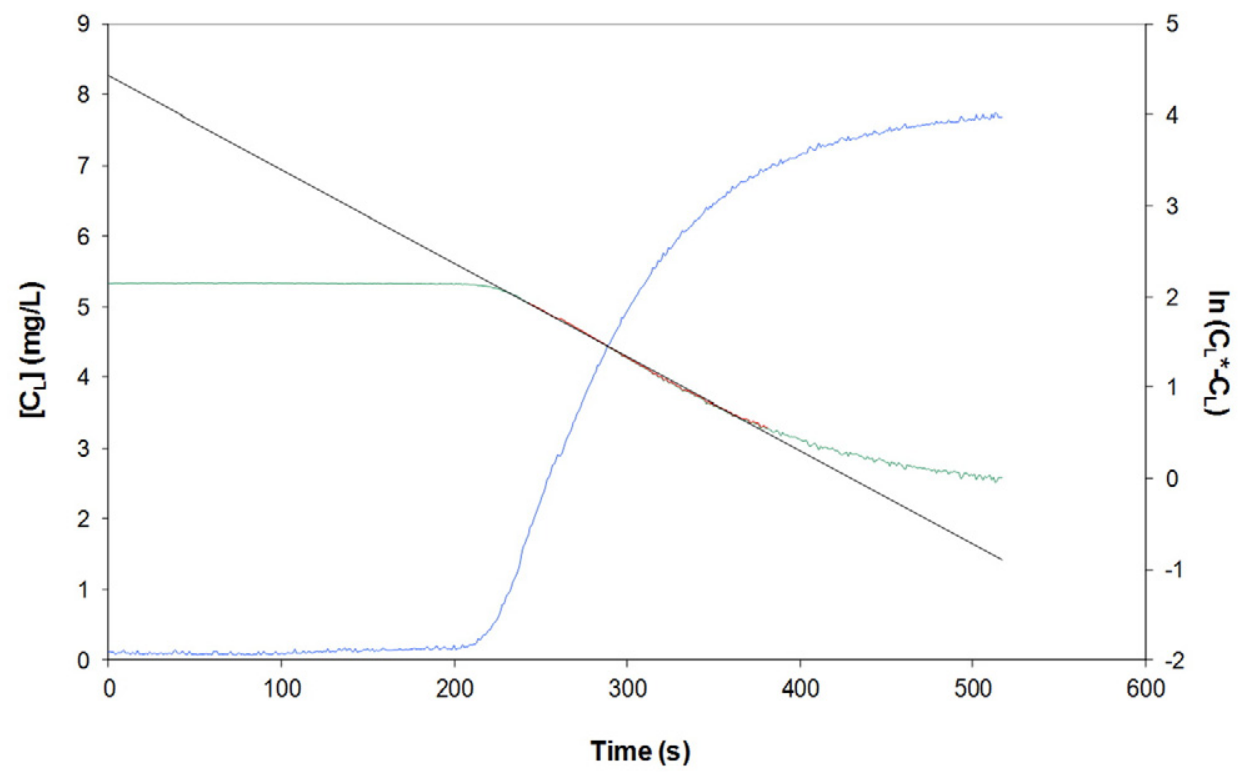

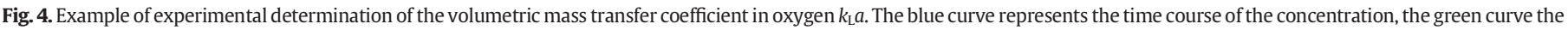

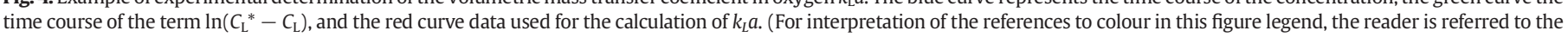
web version of this article.) 
transfer coefficient $k_{\mathrm{L}}$ a to be calculated from the time course of the dissolved oxygen concentration:

$\ln \frac{\left(C_{L}^{*}-C_{L}\right)}{\left(C_{L}^{*}-C_{L 0}\right)}=-k_{L} a \cdot t$

with $C_{\mathrm{LO}}$ the initial dissolved oxygen concentration when air is injected.

The gas phase was injected at the bottom of the reactor, i.e. counter to the liquid flow down the tilted surface. For greater accuracy, only dissolved oxygen concentrations between $20 \%$ and $80 \%$ of the equilibrium concentration were considered in the calculation [34]. The oxygendeoxygenation technique also implies rapidly (ideally instantaneously) switching the gas phase used for deoxygenation $\left(\mathrm{N}_{2}\right)$ to the gas phase composition applied during the oxygenation phase. This condition is easy to meet in airlift systems where the residence time of the gas phase is short. For the AlgoFilm $\odot$ PBR, because the gas phase volume is much greater than that of the liquid phase, the glass plate was removed just before the oxygenation phase, allowing the ambient air to replace the gas phase instantaneously, and was then reinstalled just before the switch to air injection.

Measurements of volumetric mass transfer coefficient in oxygen $k_{\mathrm{L}} \mathrm{a}$ were made in deionized water. Dissolved oxygen concentration was measured using an oxygen probe (InPro 6800, Mettler Toledo, USA) connected to a transmitter (M300, Mettler Toledo, USA). This probe was located at the beginning of the recirculation loop. The gas phase flow rate was controlled and regulated by a mass flow meter (Bronkhorst, France).

An example of an experimental result is presented in Fig. 4. The influence of the operating parameters of the AlgoFilm@ $\odot$ PBR such the gas flow rate, the liquid flow rate, the tilt angle, the gas flow direction and the total volume of the liquid phase were investigated. As the dissolved oxygen concentration at equilibrium varies with the liquid phase temperature, all the $k_{\mathrm{L}}$ a values were expressed relative to the standard temperature of $20^{\circ} \mathrm{C}$ to facilitate comparison of the results [34]. This was done using the following relation:

$k_{L} a_{20}{ }^{\circ} \mathrm{C}=k_{L} a_{T} \cdot 1,024^{20-T}$.

Each experiment presented below was carried out in triplicate, and $k_{\mathrm{L}} \mathrm{a}_{20^{\circ} \mathrm{C}}$ values are averages.

\subsection{Microalgal culture}

\subsubsection{Microalga and culture medium}

The strain used for AlgoFilm $\odot$ validation was C. vulgaris (211/19 SAG). The autotrophic Sueoka medium [35] described by Harris [36] was used. High volumetric productivity implies adjusting medium composition so as to avoid mineral limitation $[11,37,38]$. In practice, this was not so easy. Firstly, because of the high nutrient supply requirements, non-assimilated ions (especially $\mathrm{Na}^{+}$and $\mathrm{Cl}^{-}$, the two predominant ones) tended to accumulate in the culture medium and generate a drift during the PBR operation, with formation of salt crystals. This problem was solved by replacing $\mathrm{NH}_{4} \mathrm{Cl}$ and $\mathrm{NaHCO}_{3}$ by $\mathrm{NH}_{4} \mathrm{HCO}_{3}$. Secondly, nutrient concentration had to be increased (standard medium composition usually being designed to reach a maximal dry-weight biomass concentration of around $3-4 \mathrm{~kg} \cdot \mathrm{m}^{-3}$ ). Nutrient concentrations in the growth medium were then increased to enable high biomass concentrations, as obtained in the AlgoFilm@ PBR. The same procedure as that described in [38] was applied, based on monitoring nutrient consumption by anionic chromatography during a batch culture (see this work for more details). Consumption were measured for three different biomass concentrations: $7.6,16.5$ and $30.5 \mathrm{~kg} \cdot \mathrm{m}^{-3}$. This allowed determining the yields of nutrients assimilation into biomass. The results are presented in Table 1. We note that the high biomass concentrations obtained significantly reduced uncertainties in the main nutrient assimilation rates. Hutner's trace elements solution [36] was also added in excess
Table 1

Yields of assimilation of main ions during the biomass synthesis (mass).

\begin{tabular}{ll}
\hline Ion & \% assimilated during the biomass growth (mean $\pm \mathrm{SD}$ ) \\
\hline $\mathrm{PO}_{4}^{2-}$ & $4.74 \pm 0.3$ \\
$\mathrm{SO}_{4}^{2-}$ & $2.73 \pm 0.1$ \\
$\mathrm{NH}_{4}^{+}$ & $16.53 \pm 0.2$ \\
$\mathrm{~K}^{+}$ & $1.79 \pm 0.2$ \\
$\mathrm{Mg}^{2+}$ & $0.54 \pm 0.01$ \\
$\mathrm{Ca}^{2+}$ & $0.08 \pm 0.01$ \\
\hline
\end{tabular}

( $0.5 \mathrm{~mL}$ for $1 \mathrm{~L}$ of culture medium). No visible limitation by trace elements was observed.

For all cultures in PBR, $\mathrm{pH}$ and temperature were controlled at 7.5 (automatic $\mathrm{CO}_{2}$ injection) and $25{ }^{\circ} \mathrm{C}$ (automatic air draft on the rear side).

\subsubsection{Biomass analyses}

3.3.2.1. Biomass dry weight. Depending on the cell concentration, 0.4-10 $\mathrm{mL}$ of algal suspension was filtered through a pre-dried preweighed glass fiber filter (Whatman GF/F, $0.7 \mu \mathrm{m}$ ). Biomass concentrate was washed with distilled water to eliminate minerals. The filter was dried at $110{ }^{\circ} \mathrm{C}$ for $24 \mathrm{~h}$, cooled in a dessicator and reweighed. The final value was the average of three replicates. Biomass concentrations were used to deduce biomass productivities from residence time value $\tau_{\mathrm{p}}$ (i.e. volumetric biomass productivity $P_{x}=C_{x} / \tau_{\mathrm{p}}$ ).

3.3.2.2. Pigment contents. Culture samples of volume $V_{1}$, containing 5 to $10 \times 10^{6} \mathrm{cells} / \mathrm{mL}$, were centrifuged $\left(13,400 \mathrm{rpm}, 10 \mathrm{~min}, 4^{\circ} \mathrm{C}\right)$. The pellet was then suspended in $V_{2} \mathrm{~mL}$ of methanol and then stored in darkness at $44{ }^{\circ} \mathrm{C}$ during 45 to $180 \mathrm{mn}$ to allow complete extraction. The cell fragments were then separated by centrifuging $(13,400 \mathrm{rpm}$, $10 \mathrm{~min}, 4^{\circ} \mathrm{C}$ ) and the optical density of the supernatant containing the pigments dissolved in acetone was measured with a spectrophotometer at 480, 652, 665 and $750 \mathrm{~nm}$ (Jenway, England or Safas MC2, Monaco)

Three replicates were prepared, and the chlorophyll $a, b$ and photoprotective carotenoids (PPC) were determined using the following relationships [39,40]:

$C_{\mathrm{Chl}-\mathrm{a}}=\left[-8.0962\left(\mathrm{OD}_{652}-\mathrm{OD}_{50}\right)-16.5169\left(\mathrm{OD}_{665}-\mathrm{OD}_{750}\right)\right] V_{2} l^{-1} V_{1}{ }^{-1}$ $C_{\mathrm{Chl}-\mathrm{b}}=\left[27.4405\left(\mathrm{OD}_{652}-\mathrm{OD}_{750}\right)-12.1688\left(\mathrm{OD}_{665}-\mathrm{OD}_{750}\right)\right] V_{2} l^{-1} V_{1}^{-1}$, $C_{\mathrm{PPC}}=\left[4.0\left(\mathrm{OD}_{480}-\mathrm{OD}_{750}\right)\right] \cdot V_{2} l^{-1} V_{1}{ }^{-1}$,

\subsection{Modeling of AlgoFilm@ performance}

The engineering parameters of Eq. (1) make possible to calculate the maximal performance values of a given culture system as a function of its design, the light received, and the strain cultivated. Such information is highly valuable for scaling the system, and was used for the initial design of the AlgoFilm@ PBR. We have, however, to bear in mind that these relations give maximal productivities, and do not allow the prediction of PBR performance as a function of operating parameters, such as residence time (i.e. dilution rate) applied in continuous or semicontinuous culture. The residence time directly influences biomass concentration in the culture system, and thereby light attenuation conditions and resulting biomass productivity. Maximal productivity is thus achieved for an optimal residence time value (see [41] for details).

To predict PBR performance variation for any value of an operating parameter (PFD, residence time, etc.), it is necessary to relate light attenuation conditions as affected by biomass concentration to resulting photosynthetic growth. Such a knowledge model has already been proposed $[7,41]$. As the engineering parameters in Eq. (1) derived directly from this knowledge model, the same corpus was also used to predict AlgoFilm@ $\odot$ PBR performance as a function of the various operating 

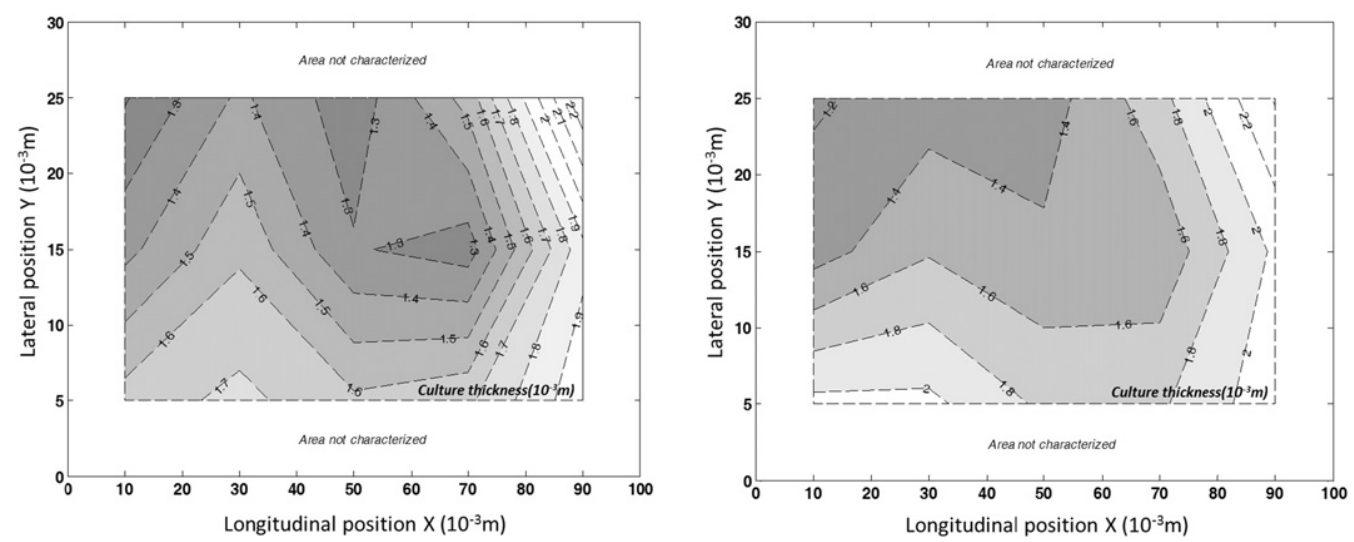

Fig. 5. Culture thickness on the inclined plane (left: $\varphi=0.62^{\circ}, \mathrm{Qm}=1543 \mathrm{~mL} / \mathrm{min}$; right: $\varphi=0.64^{\circ}, \mathrm{Qm}=2076 \mathrm{~mL} / \mathrm{min}$ ).

variables applied in the experimental study. This model is summarized in Appendix A.

\section{Results and discussion}

\subsection{Hydrodynamics and gas-liquid mass transfer characterization}

\subsubsection{Liquid-film thickness and film homogeneity}

One of the main challenges of the AlgoFilm $\odot$ concept is controlling the thickness of the culture layer falling freely down the tilted surface. Decreasing this depth will increase the specific illuminated area of the PBR and thereby raise the resulting biomass volumetric productivity. This is, however, not sufficient to ensure high productivities. In microalgae cultivation, it has also been demonstrated that full light attenuation must occur in the culture depth, as only light actually absorbed in the culture volume is converted by photosynthetic growth $[10,12,15,41]$. For a very thin culture depth, here around a few millimeters, achieving full light absorption is not simple. This difficulty is made worse in our case because of the difficulty ensuring in practice a perfectly even tilted support surface. For all these reasons, we retained a minimal limit value of culture thickness on the tilted surface of around $1.0-1.5 \mathrm{~mm}$.

To verify the evenness of the film thickness and compare its mean value with that predicted theoretically by Eq. (4), the culture thickness was mapped. Different operating conditions were tested to investigate the influence of the liquid flow rate and tilt angle of the sloping surface. Results of culture thickness are given in Fig. 5 for highest and lowest flow rates. The input of the liquid phase at the top of the inclined plane corresponds to the point $(0 ; 0)$. The results show that the local film thickness was greater in two areas. These correspond to the last outlet of the distributor at the top of the slope, and the bottom of the slope. At the top, higher film thicknesses were obtained, explained by a slightly higher flow rate from the last orifice of the distributor. At the bottom, the junction between the bottom of the slope and the collector tank forms an angle, increasing the film thickness in this area.

Culture thicknesses obtained from local measurements (needle contact method) were compared with the value obtained from the liquid volume determination on the inclined surface. This value was deduced from the total volume introduced into the reactor, minus the recirculation loop volume, which is constant and easily determined from set-up characteristics (i.e. filled volume). All values are summarized in Table 2. Because of the less even culture thickness at the bottom of the tilted surface, Table 2 also presents average values for positions higher on the slope.

Disregarding the lower part of the tilted surface, the average thicknesses obtained from local measurements were found to be very close to those obtained with the volume-based method. Table 2 also gives the film thickness predicted by the hydrodynamic model (Eq. (4)). We note that the experimental values are slightly higher than those derived from the model. This can easily be explained by the assumptions of the model. Even so, the difference remains in the accuracy range of methods used here. Both experimental and theoretical determinations of the liquid film thickness can thus be retained. In addition, the experimental method based on the liquid volume on the tilted surface was found to be a simple way to determine film thickness.

At this stage of the study, although film thickness evenness could be improved on the overall tilted surface, it was considered satisfactory. The range of values obtained was $1.3-2.2 \mathrm{~mm}$, in line with our initial design constraint (minimal depth of culture of around 1.0-1.5 mm).

\subsubsection{Gas-liquid mass transfer}

All the operating parameters of the AlgoFilm@ PBR that could influence gas-liquid mass transfer were investigated: liquid flow rate, tilt angle of the support surface, and gas phase injection.

Regarding the influence of gas phase injection, three flow rates from 100 to $1000 \mathrm{~mL} / \mathrm{min}$ were applied while keeping constant the other operating conditions, such as the liquid flow rate and the tilt angle of the reactor, and so the total liquid volume in the reactor (Table 3; trials $2-4) . k_{L} a_{20^{\circ} \mathrm{C}}$ values were found to be relatively independent of the gas phase flow rate: a deviation of $<8 \%$ (confident interval of $95 \%$ ) was observed on the three $k_{L} a_{20^{\circ} \mathrm{C}}$ values measured. To check possible influence of the flow direction of the gas phase, the air input was connected at the top of the tilted surface so that the gas flow was co-current with the liquid phase flow. No significant influence was observed on $k_{L} a_{20}{ }^{\circ} \mathrm{C}$ values, with a difference of $<5 \%$ compared with the counter-current case (Table 3; trials 3 and 6). Finally, $k_{L} a_{20}{ }^{\circ} \mathrm{C}$ was also measured without the transparent glass plate used for culture confinement. In this last configuration, the AlgoFilm@ $\odot$ PBR was comparable to an open system configuration. The $k_{L} a_{20^{\circ} \mathrm{C}}$ values were identical to those obtained with the glass installed (Table 3; trials 1-4).

All these results finally demonstrate that the gas-liquid mass transfer is not driven by the gas phase injection, but by the interfacial gasliquid area on the tilted surface. For the rest of the gas-liquid mass

Table 2

Experimental and theoretical values of the film thickness $\mathrm{L}_{\mathrm{z}}$ (experimental accuracy: $0.05 \mathrm{~mm}$; IC95 of the model: $0.07 \mathrm{~mm}$ ).

\begin{tabular}{|c|c|c|c|c|c|c|}
\hline & $\varphi\left({ }^{\circ}\right)$ & $\mathrm{Q}_{\mathrm{m}}(\mathrm{mL} / \mathrm{min})$ & $\mathrm{L}_{\mathrm{z}}(\mathrm{mm})$ average on 15 areas & $\mathrm{L}_{\mathrm{z}}(\mathrm{mm})$ average on 12 areas & $\mathrm{L}_{\mathrm{z}}(\mathrm{mm})$ ratio $\mathrm{V} / \mathrm{S}$ & $\mathrm{L}_{\mathrm{z}}(\mathrm{mm})$ model \\
\hline Trial 1 & 0.62 & 1543 & 1.58 & 1.46 & 1.44 & 1.34 \\
\hline Trial 2 & 1.70 & 1673 & 1.01 & 1.02 & 0.99 & 0.99 \\
\hline Trial 3 & 0.64 & 2076 & 1.70 & 1.58 & 1.53 & 1.47 \\
\hline
\end{tabular}


Table 3

Synthesis of experimental results to characterize gas/liquid mass transfer. (a) Trial without the glass plate (equivalent to an open system); (b) co-current air injection.

\begin{tabular}{|c|c|c|c|c|c|c|c|c|c|}
\hline $\begin{array}{l}\text { Trial } \\
\left(n^{\circ}\right)\end{array}$ & $\begin{array}{l}\text { Gas flow rate } \\
\mathrm{Q}_{\mathrm{g}}(\mathrm{mL} / \mathrm{min})\end{array}$ & $\begin{array}{l}\text { Liquid flow rate } \\
\mathrm{Q}_{\mathrm{m}}(\mathrm{mL} / \mathrm{min})\end{array}$ & $\begin{array}{l}\text { Inclination of the } \\
\text { inclined surface } \varphi \\
\left({ }^{\circ}\right)\end{array}$ & $\begin{array}{l}\text { Liquid } \\
\text { volume } \\
(\mathrm{mL})\end{array}$ & $\begin{array}{l}\text { Mass transfer } \\
\text { coefficients } k_{L} a_{20^{\circ} \mathrm{C}} \\
\left(\mathrm{s}^{-1}\right)\end{array}$ & $\begin{array}{l}\text { Confiance } \\
\text { interval 95\% } \\
\left(\mathrm{s}^{-1}\right)\end{array}$ & $\begin{array}{l}\text { Interfacial } \\
\text { exchange area a } \\
\left(\mathrm{m}^{-1}\right)\end{array}$ & $\begin{array}{l}\text { Mass transfer } \\
\text { coefficients } k_{L 20^{\circ} \mathrm{C}} \\
\left(\mathrm{s}^{-1}\right)\end{array}$ & $\begin{array}{l}\text { Confiance } \\
\text { interval 95\% } \\
\left(\mathrm{s}^{-1}\right)\end{array}$ \\
\hline $1^{(a)}$ & 0 & 1550 & 0.5 & 630 & $1.06 \cdot 10^{-2}$ & $1.30 \cdot 10^{-3}$ & 476 & $2.22 \cdot 10^{-5}$ & $3.09 \cdot 10^{-6}$ \\
\hline 2 & 100 & 1550 & 0.5 & 630 & $1.01 \cdot 10^{-2}$ & $2.37 \cdot 10^{-4}$ & 476 & $2.12 \cdot 10^{-5}$ & $8.34 \cdot 10^{-7}$ \\
\hline 3 & 500 & 1550 & 0.5 & 630 & $1.04 \cdot 10^{-2}$ & $6.94 \cdot 10^{-4}$ & 476 & $2.18 \cdot 10^{-5}$ & $1.80 \cdot 10^{-6}$ \\
\hline 4 & 1000 & 1550 & 0.5 & 630 & $1.09 \cdot 10^{-2}$ & $9.87 \cdot 10^{-4}$ & 476 & $2.28 \cdot 10^{-5}$ & $2.43 \cdot 10^{-6}$ \\
\hline 5 & 500 & 1550 & 0.5 & 1300 & $5.84 \cdot 10^{-3}$ & $3.23 \cdot 10^{-4}$ & 254 & $2.30 \cdot 10^{-5}$ & $1.45 \cdot 10^{-6}$ \\
\hline $6^{(\mathrm{b})}$ & 500 & 1550 & 0.5 & 630 & $9.91 \cdot 10^{-3}$ & $7.12 \cdot 10^{-4}$ & 476 & $2.08 \cdot 10^{-5}$ & $1.83 \cdot 10^{-6}$ \\
\hline 7 & 500 & 1000 & 0.5 & 560 & $1.05 \cdot 10^{-2}$ & $2.26 \cdot 10^{-4}$ & 536 & $1.96 \cdot 10^{-5}$ & $7.72 \cdot 10^{-7}$ \\
\hline 8 & 500 & 2000 & 0.5 & 660 & $1.34 \cdot 10^{-2}$ & $7.72 \cdot 10^{-4}$ & 455 & $2.96 \cdot 10^{-5}$ & $2.15 \cdot 10^{-6}$ \\
\hline 9 & 500 & 1550 & 1.5 & 472 & $1.28 \cdot 10^{-2}$ & $7.02 \cdot 10^{-4}$ & 636 & $2.01 \cdot 10^{-5}$ & $1.53 \cdot 10^{-6}$ \\
\hline
\end{tabular}

transfer characterization, the gas flow rate was kept at $500 \mathrm{~mL} / \mathrm{min}$ in counter-current.

The influence of the liquid phase flow rate on gas-liquid mass transfer was then analyzed. We note that the influence of this parameter is more complex, because it can affect both gas-liquid mass transfer and liquid film thickness (Eq. (4)). Assuming a perfectly smooth surface of the liquid phase on the tilted surface, it is possible to estimate the volumetric interfacial exchange area (noted $a, \mathrm{~m}^{2} \cdot \mathrm{m}^{-3}$ ) and thus the mass transfer coefficient $k_{L 20^{\circ} \mathrm{C}}\left(k_{L} a_{20^{\circ} \mathrm{C}}=k_{L 20^{\circ} \mathrm{C}} \cdot a\right)$. For each test (Table 3; trials 3, 7 and 8), the mass transfer coefficient $k_{\mathrm{L} 20^{\circ} \mathrm{C}}$ was then calculated.

Over the flow rate range tested $(1000-2000 \mathrm{~mL} / \mathrm{min})$ and in this configuration $\left(\alpha=0.5^{\circ}\right)$, the mass transfer coefficient $k_{L 20^{\circ} \mathrm{C}}(\mathrm{m} / \mathrm{s})$ was found to depend on the liquid phase flow rate. This is explained by the fact that the liquid phase flow rate influences volume on the tilted surface (and so the total volume), and also residence time in each part of the reactor. The PBR geometry is composed of different sections each with a different influence on the transfer (the recirculation loop is confined and unaerated, while the liquid phase on the tilted surface is in contact with the gas phase). The improvement of the transfer on increasing the liquid phase flow rate can then be explained by a longer contact time between gas and liquid phases on the tilted surface. Thus the greater the liquid phase flow rate, the greater the contact time, and so the more efficient the transfer is. As a direct consequence, a correlation between $k_{L 20^{\circ} \mathrm{C}}(\mathrm{m} / \mathrm{s})$ and $Q_{\mathrm{m}}(\mathrm{mL} / \mathrm{min})$ can then be proposed:

$k_{L_{20^{\circ} \mathrm{C}}}=9.78 \cdot 10^{-9} \cdot Q_{\mathrm{m}}+8.82 \cdot 10^{-6}$

We note that this empirical relation (Eq. (7)) can be combined with the hydrodynamic model (Eq. (4)), enabling us to calculate the liquid flow rate as a function of operating parameters, and therefore the volumetric interfacial exchange area $a$. This enables us to predict $k_{L 20^{\circ} \mathrm{C}}$ values. However, all the parameters were found to be related. This can be illustrated by modifying, for example, the tilt angle (Table 3, trials 3

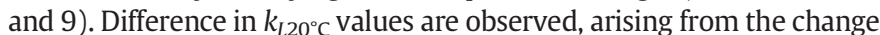
in the volumetric interfacial exchange area $a$ (a lower liquid volume being obtained by increasing the tilt angle), but also from a modification of the residence time in each section of the reactor. With the lowest tilt angle, residence time on the slope is greater, leading to a higher value of $k_{L 20^{\circ} \mathrm{C} \text {. }}$

Finally, the effect of the liquid phase volume, and therefore the volumetric interfacial area of exchange $a$, was specifically evaluated. The liquid phase volume was deliberately doubled compared with the normal use of the reactor (Table 3; trials 3 and 5 ). The experiment showed that the $k_{L} \mathrm{a}_{20}{ }^{\circ} \mathrm{C}$ values were halved. This result validates the above considerations: considering the articular configuration of the AlgoFilm@ PBR, increasing the liquid volume has negligible influence on the mass

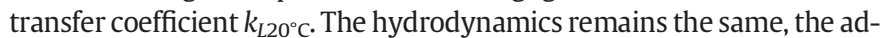
ditional volume of liquid ending up at the bottom of the slope in the collector tank. On the other hand, this directly reduces the specific area. As a consequence, the $k_{L} \mathrm{a}_{20^{\circ} \mathrm{C}}$ value is halved.
Whatever the conditions, the gas-liquid mass transfer performance was finally found to be easy to predict. By combining Eq. (7) to predict the mass transfer coefficient $k_{L 20^{\circ} \mathrm{C}}$ and Eq. (4) to predict the surface exchange area $a$ from operating parameters (i.e. ratio of tilted surface area to the total culture volume), the volumetric mass transfer coefficient $k_{L}$ a can be easily deduced $\left(k_{L} a=k_{L} a\right)$.

As a final step in this part of the study, we investigated whether these gas-liquid mass transfer performance levels were sufficient to avoid oxygen over-accumulation in the culture system, which might have a negative impact on resulting photosynthetic growth. For that purpose, the same approach as described in Loubiere et al. [42] for the design of a PBR for microalgal biomass production in hatcheries was applied. This is based on the comparison between the oxygen production during photosynthetic growth, and the oxygen physically transferable from liquid to gas phases (by desorption). Oxygen production $\left(P_{\mathrm{O}_{2}}\right)$ is proportional to growth rate and volumetric productivity $P_{V}$ in steadystate:

$P_{O_{2}}=Y_{O_{2} / x} P_{V}$

with $\mathrm{Y}_{\mathrm{O}_{2} / x}$ the specific yield of oxygen production $\mathrm{Y}_{\mathrm{O}_{2} / x}=v_{\mathrm{O}_{2}-X} \frac{M_{\mathrm{O}_{2}}}{M_{X}}$, around $1.5-2 \mathrm{~kg}$ of oxygen per $\mathrm{kg}$ of biomass).

By keeping the more constraining values $\left(\mathrm{Y}_{\mathrm{O}_{2}} / \mathrm{x}=2\right.$, volumetric productivities in the range of $10 \mathrm{~kg} \cdot \mathrm{m}^{-3} \cdot$ day $^{-1}$ ), this would lead to an oxygen production of $20 \mathrm{~kg} \cdot \mathrm{m}^{-3} \cdot$ day $^{-1}$.

This value has to be compared with the aeration performance of the PBR, given by Eq. (5). At steady state, a mass balance for oxygen leads to:

$N_{\mathrm{O}_{2}}=P_{\mathrm{O}_{2}}$

This enables us to calculate the oxygen concentration in the culture medium:

$C_{L}=\frac{Y_{o_{2} / x} P_{X}}{k_{L} a}+C_{L}^{*}$

with $C_{L}^{*}$ the value of dissolved oxygen concentration at equilibrium with the gas phase (around $7.10^{-3} \mathrm{~kg} \cdot \mathrm{m}^{-3}$ in the case of air).

Using a gas/liquid mass transfer of $1.10^{-2} \mathrm{~s}^{-1}$ (the lowest value obtained), this leads to an oxygen concentration in the culture medium of $C_{\mathrm{L}}=7.5 .10^{-3} \mathrm{~kg} \cdot \mathrm{m}^{-3}$. This value is thus very close to that obtained at equilibrium with air ( $<10 \%$ increase), and we can expect no negative effect on growth. For example, Torzillo et al. [43] reported no loss of productivity with Spirulina platensis for $C_{L}$ at around $20.10^{-3} \mathrm{~kg} \cdot \mathrm{m}^{-3}$, while Marquez et al. [44] observed a loss of productivity for $C_{L}>$ $40.10^{-3} \mathrm{~kg} \cdot \mathrm{m}^{-3}$. The design of the AlgoFilm@ PBR, by promoting a high area-to-volume ratio to obtain high volumetric productivity, also proved sufficiently efficient for gas-liquid mass transfer to avoid this possible limitation. 

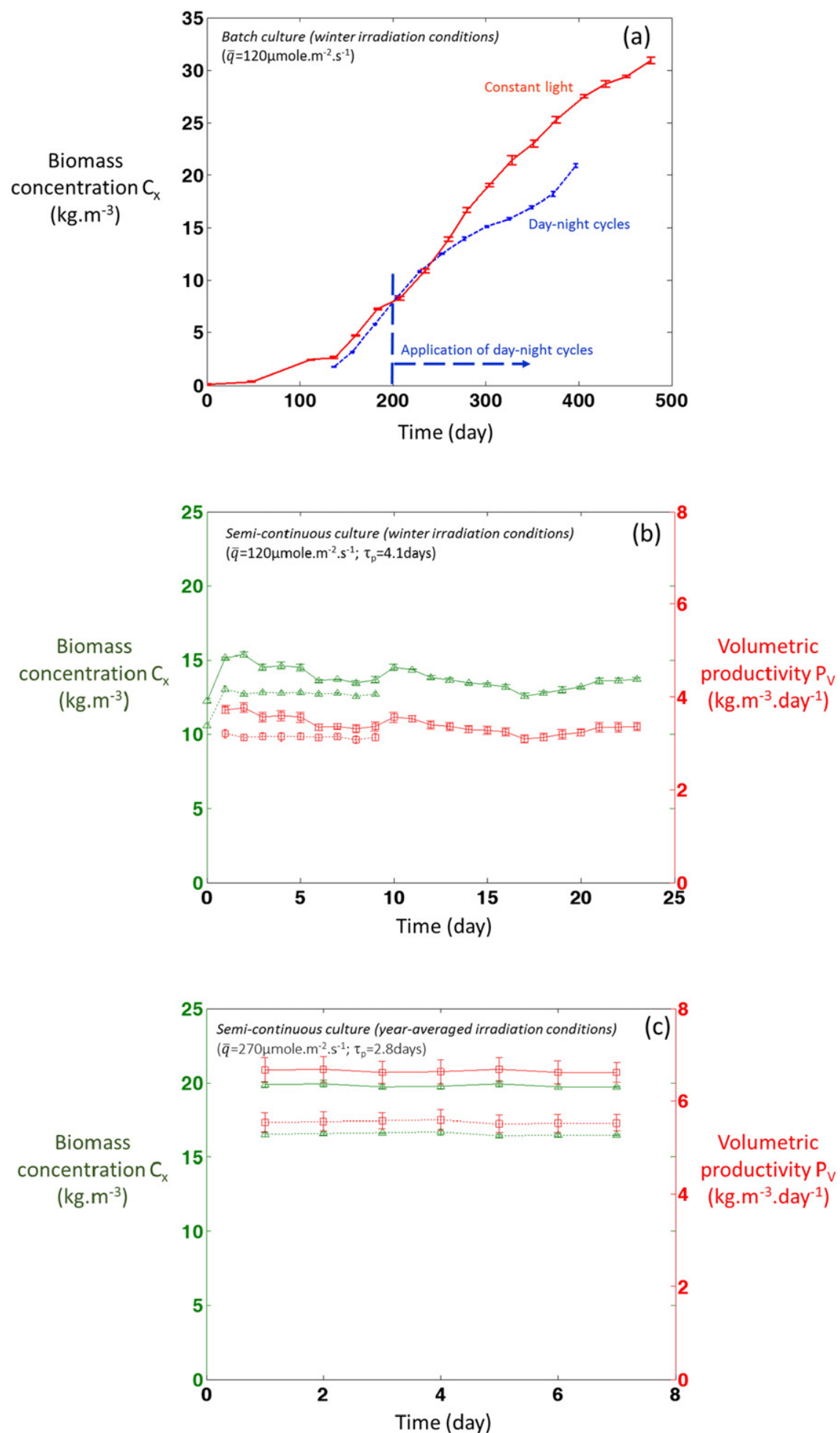

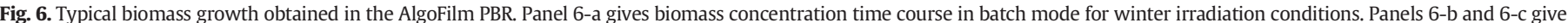

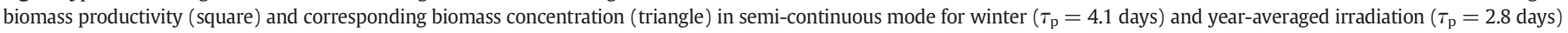
conditions respectively. For each irradiation condition, permanent illumination (solid line) and day-night cycle (dashed line) were compared.

\subsection{Experimental validation of AlgoFilm@ performance}

4.2.1. Cultivation of C. vulgaris in batch mode for constant and day-night cycles (winter period)

For all the culture experiments, operating conditions were defined from Eq. (4) so as to obtain an averaged depth of culture on the illuminated surface of around $1.5 \mathrm{~mm}$. This was obtained with a liquid flow rate $Q_{\mathrm{m}}$ of $1.6 \mathrm{~L} \cdot \mathrm{min}^{-1}$ and a tilt angle $\varphi$ of $0.5^{\circ}$ (i.e. the set-up could be considered as almost horizontal). This gave a specific illuminated surface area $a_{\text {light }}=480 \mathrm{~m}^{2} \cdot \mathrm{m}^{-3}$ (here calculated on the overall system). This also corresponds to around $2.1 \mathrm{~L}$ per $\mathrm{m}^{2}$ of illuminated surface. We note that this value illustrates the concept of "volumetric intensification". For example, a value of $100 \mathrm{~L} / \mathrm{m}^{2}$ is obtained for a culture system of depth $0.1 \mathrm{~m}$. 
Table 4

Summary of daily average biomass productivities and concentration obtained in the AlgoFilm@ PBR for the different cases studied (see text for details).

\begin{tabular}{|c|c|c|c|c|c|c|c|c|c|c|c|c|c|}
\hline \multirow[t]{3}{*}{$\begin{array}{l}\text { Irradiation } \\
\text { condition }\end{array}$} & \multirow[t]{3}{*}{$\begin{array}{l}\text { PFD (daily average value) } \\
\left(\mu \text { mole } \mathrm{m}^{-2} \cdot \mathrm{s}^{-1}\right)\end{array}$} & \multirow[t]{3}{*}{$\begin{array}{l}\text { Illumination } \\
\text { condition }\end{array}$} & \multirow{3}{*}{\multicolumn{2}{|c|}{$\begin{array}{l}\text { Residence } \\
\text { time (day) }\end{array}$}} & \multicolumn{3}{|c|}{ Biomass concentration $\left(\mathrm{kg} \cdot \mathrm{m}^{-3}\right)$} & \multicolumn{4}{|c|}{ Pigment content (\% of dry biomass) } & \multirow{2}{*}{\multicolumn{2}{|c|}{$\begin{array}{l}\text { Specific rate } \\
\text { of photons } \\
\text { absorption } \\
\left(\mu \mathrm{mole} \cdot \mathrm{g}^{-1}\right. \\
\left.\mathrm{s}^{-1}\right) \\
\text { Model } \\
\text { prediction }\end{array}$}} \\
\hline & & & & & \multirow{2}{*}{$\begin{array}{l}\text { Experiment } \\
\text { (harvesting } \\
\text { moment) }\end{array}$} & \multicolumn{2}{|c|}{ Model prediction } & \multirow{2}{*}{\multicolumn{2}{|c|}{$\begin{array}{l}\text { Experiment } \\
\text { (harvesting } \\
\text { moment) }\end{array}$}} & \multirow{2}{*}{\multicolumn{2}{|c|}{$\begin{array}{l}\text { Model prediction } \\
\text { (harvesting moment) }\end{array}$}} & & \\
\hline & & & & & & $\begin{array}{l}\text { (Harvesting } \\
\text { moment) }\end{array}$ & $\begin{array}{l}\text { (Day } \\
\text { average) }\end{array}$ & & & & & Plan & Total \\
\hline \multirow[t]{2}{*}{ Winter } & \multirow[t]{2}{*}{120} & Permanent & \multicolumn{2}{|l|}{4.1} & & 11.25 & \multirow[b]{2}{*}{10.4} & \multicolumn{2}{|c|}{$6.8 \pm 0.7 \%$} & \multicolumn{2}{|c|}{$5.78 \%$} & 7.02 & 5.44 \\
\hline & & $\begin{array}{l}\text { Day-night } \\
\text { cycle }\end{array}$ & \multicolumn{2}{|l|}{4.1} & $12.7 \pm 0.1$ & 11.35 & & \multicolumn{2}{|c|}{$5.4 \pm 0.5 \%$} & \multicolumn{2}{|c|}{$5.49 \%$} & 7.63 & 5.91 \\
\hline \multirow[t]{6}{*}{ Year-averaged } & \multirow[t]{6}{*}{270} & Permanent & \multicolumn{2}{|l|}{3.8} & - & 17.43 & & - & & 4.6 & & 10.24 & 7.93 \\
\hline & & & 2.8 & & $19.8 \pm 0.2$ & 16.43 & & $6.5 \pm$ & $0.7 \%$ & 4.5 & & 10.84 & 8.4 \\
\hline & & & 2.1 & & - & 15.15 & & - & & 4.3 & & 11.72 & 9.07 \\
\hline & & Day-night & 3.8 & & $17.8 \pm 1$ & 15.5 & 13.81 & $5 \pm$ & & 4.1 & & 12.91 & 10.00 \\
\hline & & cycle & 2.8 & & $16.5 \pm 0.3$ & 14.16 & 12.42 & - & & 3.8 & & 14.35 & 11.11 \\
\hline & & & 2.1 & & $11.7 \pm 0.3$ & 12.57 & 10.86 & $3.9 \pm$ & $0.4 \%$ & 3.4 & & 16.39 & 12.69 \\
\hline Summer & 500 & Permanent & 3.8 & & - & 23.75 & & - & & 3.9 & & 13.93 & 10.79 \\
\hline & & & 3 & & - & 23.03 & & - & & 3.9 & & 14.34 & 11.1 \\
\hline & & & 2.1 & & - & 21.48 & & - & & 3.6 & & 15.34 & 11.87 \\
\hline & & Day-night & 3.8 & & $18.9 \pm 0.3$ & 18.67 & 16.49 & $3.9 \pm$ & $0.4 \%$ & 2.6 & & 20.29 & 15.7 \\
\hline & & cycle & 3 & & $14.1 \pm 0.4$ & 17.74 & 15.48 & $3.2 \pm$ & $0.3 \%$ & 2.4 & & 21.57 & 16.7 \\
\hline & & & 2.1 & & - & 15.68 & 13.43 & - & & 2.1 & & 24.88 & 19.26 \\
\hline $\begin{array}{l}\text { Irradiation } \\
\text { condition }\end{array}$ & $\begin{array}{l}\text { PFD (daily average value) } \\
\left(\mu \mathrm{mole} \cdot \mathrm{m}^{-2} \cdot \mathrm{s}^{-1}\right)\end{array}$ & $\begin{array}{l}\text { Illumin } \\
\text { conditic }\end{array}$ & & $\begin{array}{l}\text { Resic } \\
\text { time }\end{array}$ & $\begin{array}{l}\text { ence } \\
\text { day) }\end{array}$ & $\begin{array}{l}\text { mass volumet } \\
\left.\cdot \mathrm{m}^{-3} \text { day }^{-1}\right)\end{array}$ & ric producti & ivity & $\begin{array}{l}\text { Bion } \\
\left(10^{-}\right.\end{array}$ & $\begin{array}{l}1 \text { pro } \\
-2 \cdot d\end{array}$ & $\begin{array}{l}\text { uctivity } \\
-1 \text { ) }\end{array}$ & $\begin{array}{l}\text { Model } \\
\text { predictio }\end{array}$ & n error \\
\hline & & & & & & $\begin{array}{l}\text { periment (day } \\
\text { erage) }\end{array}$ & $\begin{array}{l}\text { Model ( } \\
\text { average }\end{array}$ & day & $\begin{array}{l}\text { Expe } \\
\text { aver }\end{array}$ & & $\begin{array}{l}\text { Model (day } \\
\text { average) }\end{array}$ & & \\
\hline Winter & 120 & Perman & & 4.1 & & $2 \pm 0.07$ & 2.75 & & $7.1=$ & & 5.52 & $-17 \%$ & \\
\hline & & Day-nig & t cycle & 4.1 & & $3 \pm 0.02$ & 2.54 & & 6.66 & & 5.09 & $-19 \%$ & \\
\hline Year-averaged & 270 & Perman & & 3.8 & - & & 4.6 & & - & & 9.23 & - & \\
\hline & & & & 2.8 & & $7 \pm 0.03$ & 5.91 & & 14.1 & & 11.87 & $-16 \%$ & \\
\hline & & & & 2.1 & - & & 7.27 & & - & & 14.59 & - & \\
\hline & & Day-nig & t cycle & 3.8 & & \pm 0.1 & 3.65 & & 9.79 & & 7.29 & $-21 \%$ & \\
\hline & & & & 2.8 & & $5 \pm 0.03$ & 4.44 & & 11.8 & & 8.9 & $-20 \%$ & \\
\hline & & & & 2.1 & & \pm 0.1 & 5.17 & & 12.1 & & 10.38 & $-9 \%$ & \\
\hline Summer & 500 & Perman & & 3.8 & - & & 6.27 & & - & & 12.58 & - & \\
\hline & & & & 3 & - & & 7.74 & & - & & 15.53 & - & \\
\hline & & & & 2.1 & - & & 10.23 & & - & & 20.51 & - & \\
\hline & & Day-nig & t cycle & 3.8 & & \pm 0.03 & 4.34 & & 10.6 & & 8.71 & $-13 \%$ & \\
\hline & & & & 3 & & \pm 0.1 & 5.16 & & $10=$ & & 10.35 & $10 \%$ & \\
\hline & & & & 2.1 & - & & 6.4 & & - & & 12.84 & - & \\
\hline
\end{tabular}

Fig. 6-a shows results of biomass growth for batch culture in winter irradiation conditions. Despite the low value of PFD applied $(\bar{q}=$ $120 \mu \mathrm{mole} \cdot \mathrm{m}^{-2} \cdot \mathrm{s}^{-1}$ ), a large biomass concentration increase was observed. In around 15 days, biomass concentrations higher than
$30 \mathrm{~kg} \cdot \mathrm{m}^{-3}$ were obtained in constant light. This is of interest, as it confirms the utility of our concept for culture concentration intensification. It also validates the culture medium, which was defined so as to avoid growth limitation up to such high biomass concentration:

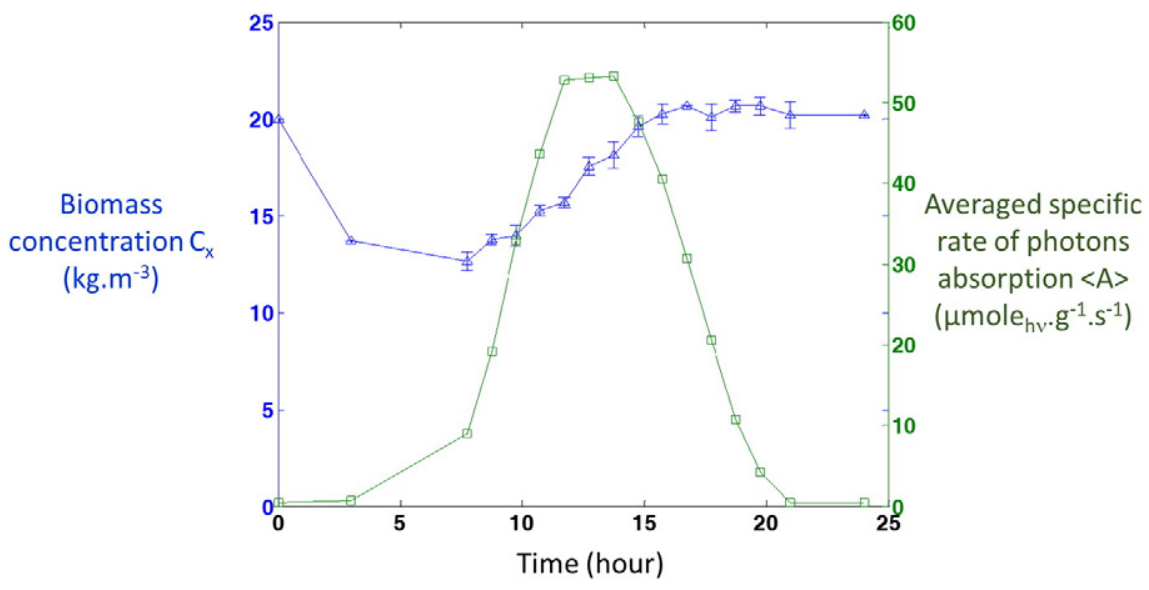

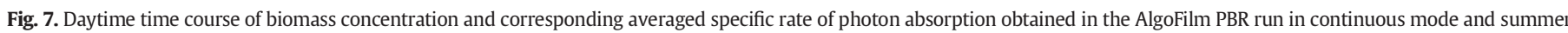
irradiation conditions. 
no significant growth rate decrease was observed even for the highest values of biomass concentration.

In a second experiment, the same procedure with constant light was conducted during the first $200 \mathrm{~h}$, and day-night cycles were then applied. As shown in Fig. 6-a, this resulted in a decrease in the growth rate, although the same averaged light energy was received on the PBR surface over a daily period. This result highlights the influence of day-night cycles on culture growth. As already discussed in [45], the dynamic time course of the day-night cycles resulted in a lower conversion efficiency compared with constant light. This is explained by the negative effect of night periods (biomass catabolism) and by the non-linear photosynthetic response to light, which causes a loss of conversion efficiency with increasing light received. As a result, conversion efficiency was lower in the middle of the day when values of PFD were higher than the daily-averaged values. However, we note that even if the growth rate was lower than in constant light, a significant biomass concentration increase was observed up to around $22 \mathrm{~kg} \cdot \mathrm{m}^{-3}$ (around $20 \%$ lower than in constant light for the same culture duration).

4.2.2. Characterization of biomass productivities in semi-continuous mode for constant and day-night cycles

Fig. 6-b and c gives results for semi-continuous culture in winter and year-averaged irradiation conditions. For the first experiment (winter irradiation condition, constant light), a long-term characterization was conducted to ensure stability of culture and biomass productivity. The steady-state was then maintained for 23 days, and no significant deviation was observed, despite the high biomass concentration achieved (in the range of $13 \mathrm{~kg} \cdot \mathrm{m}^{-3}$ ). In the remaining experiments, steady-state stability was verified at least for one week of operation.

All the results obtained at steady-state values are summarized in Table 4. The usual behavior of a PBR running in light-limited mode is observed. For a given irradiation condition, increasing the residence time leads to an increase in biomass concentration. Except for the summer irradiation condition, which has to be considered separately (see next section), we note that this resulted in all cases in an increased biomass productivity, indicating that residence time values applied in our cases (in the range 2.1-4.1 days) were below optimal values leading to maximal biomass productivities (a more thorough explanation is given in the model section). Another important result is the significant photoacclimation of $C$. vulgaris, which presents a large variation in pigment content between experiments. The highest pigment content was obtained for the lowest averaged PFD value, as obtained for winter irradiation conditions ( $6.8 \%$ of total pigment), while summer irradiation conditions gave the lowest value (3.2\%). Comparing constant and daynight cycles but for the same averaged PFD, we can also observe that day-night cycles resulted in all cases in lower pigment content. This indicated a higher light stress, as induced by the PFD variation in daynight cycles. All these observations are consistent when considering results for a given irradiation condition. When residence time decreases, biomass concentration decreases, leading to lower light attenuation conditions and thereby a decrease in pigment content. In summary, photoacclimation was influenced by PFD, light regimes (i.e. day-night cycles), and light attenuation conditions. We note that the ability of $C$. vulgaris to display strong photoacclimation (i.e. pigment adaptation) was already observed in [16]. A strong dependency on light conditions, PFD and also light spectrum was observed by these authors.

Regarding PBR performances, as for the batch culture, day-night cycles resulted in lower growth rates (i.e. productivities), although the averaged light energy remained similar for a given irradiation condition (i.e. winter, summer or year-averaged). Because of the daily harvesting biomass concentration was lower than in batch mode. However, an effect of process intensification was observed in all cases, with biomass concentration higher than $10 \mathrm{~kg} \cdot \mathrm{m}^{-3}$ (highest value around $20 \mathrm{~kg} \cdot \mathrm{m}^{-3}$ ). This led to volumetric biomass productivities higher than $3 \mathrm{~kg} \cdot \mathrm{m}^{-3} \cdot \mathrm{day}^{-1}$, the highest reported experimental values being $7.07 \mathrm{~kg} \cdot \mathrm{m}^{-3} \cdot \mathrm{day}^{-1}$ and $5.7 \mathrm{~kg} \cdot \mathrm{m}^{-3} \cdot \mathrm{day}^{-1}$ for year-averaged irradiation conditions and constant and day-night cycles respectively. Those performances were in line with the objective of setting up a PBR with a high specific illuminated surface area so as to induce high volumetric productivities. We note that for areal productivity, no significant increase in performance was observed compared with reported state-of-the-art values (between 6 and $14.10^{-3} \mathrm{~kg} \cdot \mathrm{m}^{-2} \cdot$ day $^{-1}$ ). This result is also in line with the initial design procedure, as areal productivity is not dependent on the specific illuminated surface, and can therefore only be increased by increasing the PFD.

The only discrepancy from our initial expectation concerns performance achieved for the summer irradiation conditions. Productivities were found of the same order of magnitude as with year-averaged irradiation condition, even though the averaged PFD was increased from 270 to $500 \mu \mathrm{mole} \cdot \mathrm{m}^{-2} \cdot \mathrm{s}^{-1}$. The increase in performance (around two-fold increase in both volumetric and areal productivities) when moving from winter $\left(\bar{q}=120 \mu\right.$ mole $\left.\cdot \mathrm{m}^{-2} \cdot \mathrm{s}^{-1}\right)$ to averaged irradiation conditions $\left(\bar{q}=270 \mu\right.$ mole $\left.\cdot \mathrm{m}^{-2} \cdot \mathrm{s}^{-1}\right)$ was not observed. This discrepancy is examined in detail in the next section.

\subsubsection{Specific case of summer irradiation conditions}

Experiments in summer irradiation conditions resulted in a lower increase in performance than expected. A detailed investigation was conducted, and the culture was monitored over the entire day/night cycle with hourly analysis. The same analysis as that used for the daily monitoring was used except for biomass concentration, which was estimated through $\mathrm{DO}_{750}$ measurement to reduce the total sampled volume and not perturb the process operation. Results are given in Fig. 7. We note that because of the repetition of the same day/night cycles over time, the time course of parameters presented here were found to be reproducible over a given day-night period.

This detailed daytime monitoring reveals several features. The strong relation of culture response to day/night cycle is especially shown, resulting in a fully dynamic process. Growth occurs throughout the day, while the night period results in a decrease in biomass concentration of around $7 \%\left(1 \mathrm{~kg} \cdot \mathrm{m}^{-3}\right)$. We note that this is consistent with [8, 46]. In addition, regarding culture parameters, $\mathrm{pH}$ was found to be almost constant, but a slight increase in temperature was obtained for a period of higher irradiation $\left(+6{ }^{\circ} \mathrm{C}\right)$. This was explained by the very high irradiation applied (up to $1500 \mu \mathrm{mole} \cdot \mathrm{m}^{-2} \cdot \mathrm{s}^{-1}$ ). It is clear that such a deviation in thermal regulation could induce a loss of efficiency. As shown in the literature, combining strong light and non-ideal temperature has detrimental effects on photosynthetic growth [47-51]. Furthermore, even in optimal temperature conditions, only the wide variation of irradiation during the day/night cycle has a negative influence on resulting photosynthetic conversion, as high light intensities can result in a marked loss of photosynthetic conversion, due for example to photoinhibition [19]. These negative effects related to excessive light are also closely related to light attenuation conditions in the culture volume [19-21]. It is, however, difficult to analyze accurately the exact contribution of this factor on the loss of productivity. Firstly, light attenuation conditions are directly related to incident light, biomass concentration and pigment content. All of these parameters, which interact, reveal dynamic changes during the experiment. Secondly, the AlgoFilm $\odot$ PBR induces particular light attenuation conditions, as induced by thin-film culture and high biomass concentration. As a first attempt to provide a better analysis of these interrelations, modeling can be useful. This will be the subject of the final section.

\subsection{Theoretical analysis of the AlgoFilm@ PBR}

\subsubsection{Comparison with model predictions}

The model described in the Appendix A was used to predict performance as a function of operating conditions. This model had already been validated, but only for continuous light and a conventional PBR working with a biomass concentration of few $\mathrm{kg} \cdot \mathrm{m}^{-3}$ [41]. Its first 

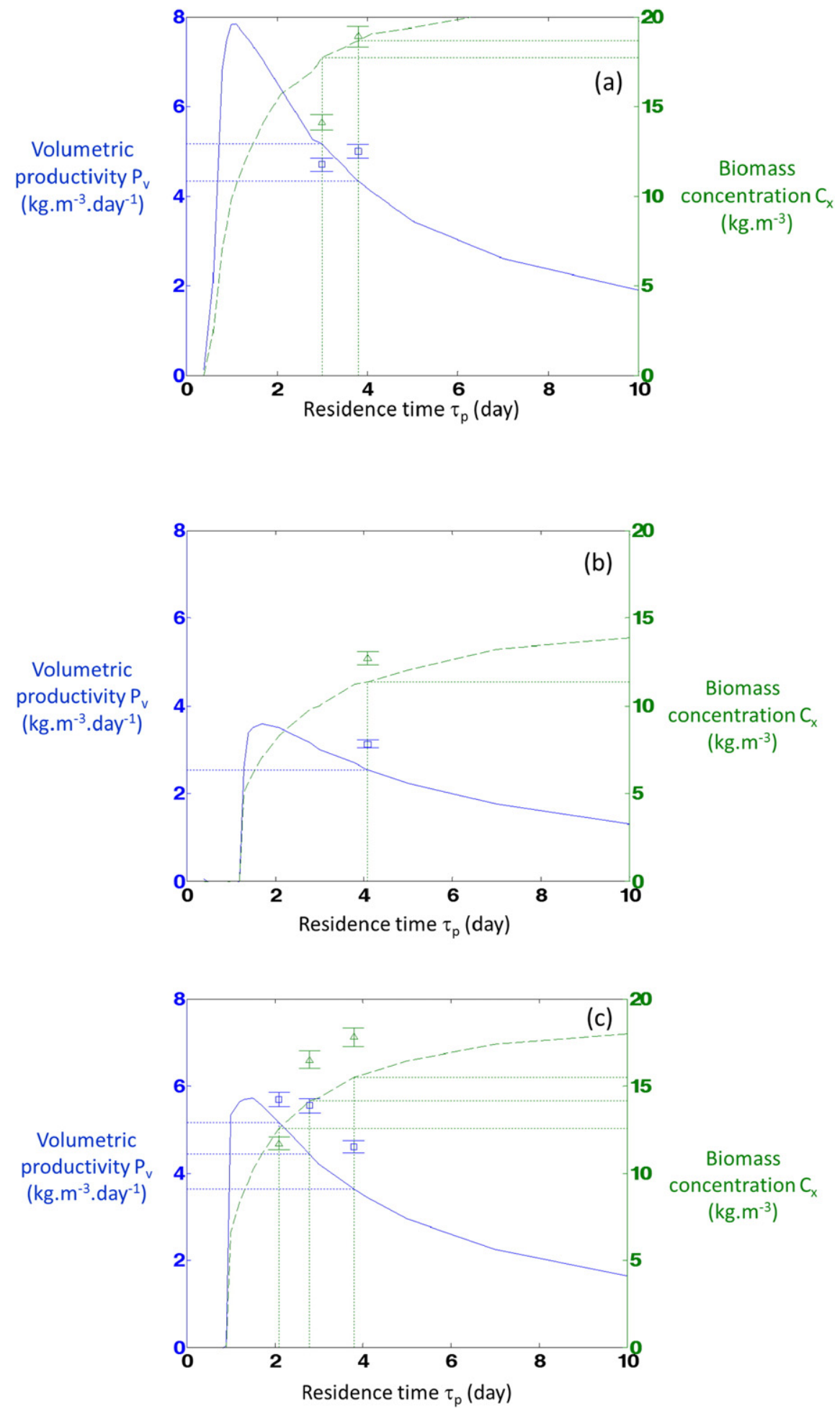

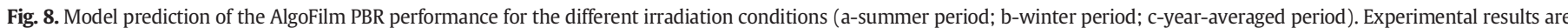
added (square and solid line for volumetric productivity; triangle and dashed line for biomass concentration).

validation for day-night cycles and high volumetric productivity PBR is presented here. It is noteworthy that this model has the same theoretical background as the engineering formulae used for the AlgoFilm@ PBR pre-scaling (Eq. (1)). The only difference is the ability of this model to predict various operating conditions, including any day-night cycles or harvesting procedures (residence time, semi-continuous mode). Pigment acclimation to light is also taken into consideration (see Appendix A for details).
Model predictions are indicated in Table 4. Except for the summer condition with lowest residence time (the case that led to the most intense light regime, as described in the previous section), model prediction tended to underestimate actual productivities, with a deviation of around $10-20 \%$. Considering the specific features of the AlgoFilm@ PBR and the wide-ranging conditions of irradiation applied, this deviation can be considered acceptable: in the case of a very thin cultures, simulation results are very sensitive to design parameters. For example, 
reducing culture depth by only $0.5 \mathrm{~mm}$ (roughly the measurement accuracy of this dimension), would increase biomass productivity by $25 \%$. Hence better prediction accuracy cannot be readily envisaged. We also have to bear in mind that the model is fully predictive, and does not include any fitting parameter. Hence the achievement of expected productivities with a deviation of at most $20 \%$ compared with initial prediction can be considered as a very positive result, emphasizing the utility of the overall model-assisted design approach applied in this work.

\subsubsection{Theoretical analysis of light regimes encountered in AlgoFilm@ during summer operation}

As observed previously, experiments reveal an apparent loss of efficiency for the more drastic summer irradiation conditions investigated (especially with the lowest residence value $\tau_{\mathrm{p}}=3$ days). After the analysis conducted previously on the daytime time course of culture parameters, the model was applied to retrieve complementary data. By definition, the model allows the calculation of light transfer conditions in culture volume as a function of operating conditions, such as PFD, biomass concentration and pigment content. This in particular allows the calculation of the specific rate of photon absorption, which was found to be relevant to the analysis of photosynthetic response to light [16, $52]$. For convenience, only values averaged on the culture volume $(\langle A\rangle)$ are presented (see Appendix A for details).

Table 4 presents averaged values of the specific rate of photon absorption for all cases (space averaging on culture volume, and time averaging on full day-night cycles). Because of the AlgoFilm@ design, values were presented for the total culture volume, and also only for the slope as the important part of the system presenting the highest intensification and contribution in the overall system. The effect of irradiation conditions and residence time is shown. Increasing PFD and decreasing residence time leads in both cases to an increase in the specific rate of photon absorption. A 3-fold increase was observed going from winter to summer. Although less significant, the decrease in residence time for a given irradiation condition also increased the specific rate of photon absorption by acting directly on biomass concentration (around 50\% increase for each irradiation condition). This result can be related to the concomitant increase in biomass productivity. Reducing biomass concentration and then light attenuation in the culture volume leads to an increased rate of photon absorption and thereby productivity. This occurs in all cases, except for the summer condition, with the lowest residence time. We note that this case also corresponds to the highest value of specific rate of photon absorption obtained in our study (around $20 \mu \mathrm{mole} \cdot \mathrm{g}^{-1} \cdot \mathrm{s}^{-1}$ on the slope). This thus supports the hypothesis of an oversaturation by light, which may have caused a reduction of photosynthetic conversion efficiency. This factor was already discussed in [45] as a generic problem of solar culture operation. The decrease in light attenuation condition tends to benefit biomass productivity, but leads to a progressive increase in photon absorption rate by the culture, which can induce biological drift if this value is too high (increased dissipation in antennas or photoinhibition). This is especially the case for solar culture presenting large dynamics in PFD, as for the summer irradiation conditions. As a result, a compromise has to be found in light attenuation conditions. However, this implies tight control of the culture system (i.e. biomass concentration and residence time), and also a better understanding of the effect of high values of the rate of photon absorption on the photosynthetic conversion. This problem is obviously far from trivial. In addition to the complex biological mechanisms involved under strong light, in solar culture, the process is fully dynamic, and so transient biological conversion mechanisms are certainly induced. To illustrate this, the time variation of the specific rate of photon absorption is added in Fig. 7 (using the same methodology of model-based calculation, see Appendix A for details). A variation from 0 (night) to $>50 \mu$ mole $_{\mathrm{h} \nu} \mathrm{g}^{-1} \cdot \mathrm{s}^{-1}$ was observed over a day's operation. This thus corresponds to strong, fast dynamics. Its exact impact on photosynthetic conversion remains to be elucidated.

\subsubsection{Estimation of maximal performance of the AlgoFilm(C) PBR}

To round off this study, we used the model to extend prediction of AlgoFilm@ PBR performance for a larger set of residence times. Because the model does not consider biological effects of very strong light (e.g. photoinhibition), our aim was to estimate maximal performance of the PBR in cases when these effects could be neglected. We also note that calculations were limited to the Nantes location (France).

Results are given in Fig. 8 for the three irradiation conditions investigated. These results show that maximal performance levels were not reached in all cases. Maximal volumetric productivities of 3.5, 5.7 and $8 \mathrm{~kg} \cdot \mathrm{m}^{-3} \cdot$ day $^{-1}$ could be envisaged for winter, year-averaged and summer irradiation conditions respectively. In practice, such performance would certainly be very difficult or even impossible to achieve, especially in intense irradiation conditions as discussed above. However, they give a good estimate of the potential of the AlgoFilm@ $\odot$ PBR. Future studies will work to improve operating procedures to bring performance closer to the limit values.

\subsubsection{Discussion of AlgoFilm@ PBR performance for photoautrophic culture and comparison with heterotrophic production of microalgal biomass (fermentation)}

Microalgae are usually produced in photoautotrophic conditions to benefit from the intrinsic advantages of photosynthetic growth, namely light conversion into biomass through $\mathrm{CO}_{2}$ and mineral nutrient fixation. In this regard, the maximal productivity experimentally achieved in this study was significantly higher than that reported in the literature for photosynthetic growth (usually around $1-2 \mathrm{~kg} \cdot \mathrm{m}^{-3} \cdot$ day $^{-1}$ for solar PBR).

This is then interesting to relate those performances to microalgae fermentation processes. For example, Behrens [53] compared phototrophic and fermentation productions. They reported volumetric productivities of $5.8 \mathrm{~kg} \cdot \mathrm{m}^{-3}$. day ${ }^{-1}$ for fermentation with biomass concentration up to around $70-100 \mathrm{~kg} \cdot \mathrm{m}^{-3}$. These values illustrate the main utility of producing microalgal biomass through fermentation, which is to obtain high biomass concentrations and high volumetric productivities (areal productivity is not meaningful as light is not used). We also note that because of sterilization constraints, fermenters also usually operate in batch or fed-batch mode.

To conclude the study, the AlgoFilm $\odot$ PBR was then described in following sections with regard to the three main features of fermentation processes, namely biomass concentration, volumetric productivity, and operating mode. Differences in terms of metabolites to be produced were deliberately not considered, such information being already available in the literature and not directly related to the AlgoFilm@ technology, but rather to the difference between phototrophic and heterotrophic growth in general.

Regarding the operating mode and achievable biomass concentration (the two being closely related), batch culture in fermenters allows a high biomass concentration in the range $70-120 \mathrm{~kg} \cdot \mathrm{m}^{-3}$ to be reached [54]. Such high biomass concentration is explained by the lack of light limitation, growth being heterotrophic and then limited by organic substrate or by oxygen availability. High biomass concentration could be of interest especially for downstream processing, by reducing the requirement for culture dewatering. In the AlgoFilm@ $\odot$ PBR, the maximal biomass concentration achieved was lower $\left(32 \mathrm{~kg} \cdot \mathrm{m}^{-3}\right.$, see Fig. 6). Higher values can however be expected. In our study, only the lowest irradiation condition was tested in batch mode (winter) and the culture was stopped before the stationary phase was obtained. This was because batch culture mode was not found suitable for a culture system like AlgoFilm@ because of medium formulation difficulties caused by such high biomass concentration (similar to fermentation, where fed-batch mode is often preferred to avoid this problem). Continuous (or semi-continuous) mode was thus favored, with the additional utility of allowing operating conditions to be set to optimize light attenuation conditions and thereby biomass productivities, which is known to be of primary relevance in phototrophic culture. We also note that 
continuous (or semi-continuous) culture in phototrophic growth is rather simple to implement for robust production even at an industrial scale, especially when compared with the heterotrophic case because of lower risk of contamination. Hence continuous or semi-continuous culture appear to be the most efficient operating modes of the AlgoFilm( PBR. However, as a consequence, a lower biomass concentration than in fermentation will be obtained in the harvest in all cases (around $15-20 \mathrm{~kg} \cdot \mathrm{m}^{-3}$, see Fig. 8).

Regarding kinetics performance, like for any production process, productivity is clearly of primary relevance, as it directly defines the amount of product (i.e. biomass) delivered over a given period of exploitation. Because of light attenuation in the culture bulk, phototrophic culture in a PBR is often described as having low volumetric productivity. Behrens [53], for example, reported a value of $0.4 \mathrm{~kg} \cdot \mathrm{m}^{-3} \cdot$ day $^{-1}$ for phototrophic growth (we note this value is one of order of magnitude below the productivity obtained in this study for the AlgoFilm@ PBR, illustrating the gain achieved with this device). For heterotrophic growth in fermenters, a wide range of biomass productivities can be found in the literature, depending on the strain, the optimization effort and the scale of production (i.e. from flasks to fermenters of a few $\mathrm{m}^{3}$ ). As discussed in [54], volumetric productivity in fermenters is also strongly influenced by the organic substrate feeding strategy. For example, $\mathrm{Wu}$ and Shi [55] obtained with C. pyrenoidosa a biomass concentration of $116 \mathrm{~kg} \cdot \mathrm{m}^{-3}$ at an average productivity of $1.02 \mathrm{~kg} \cdot \mathrm{m}^{-3} \cdot \mathrm{h}^{-1}$. Similarly, Graverholt and Eriksen [56] reported an average productivity of approximately $0.33 \mathrm{~kg} \cdot \mathrm{m}^{-3} \cdot \mathrm{h}^{-1}$, and $\mathrm{Xu}$, Miao and $\mathrm{Wu}$ [57] a value of $0.1 \mathrm{~kg} \cdot \mathrm{m}^{-3} \cdot \mathrm{h}^{-1}$. All these values should be expressed on a daily basis to compare with the AlgoFilm@ $\odot$ PBR. A range of productivity from 2 to $24 \mathrm{~kg} \cdot \mathrm{m}^{-3}$. day ${ }^{-1}$ should then be obtained. We note, however, that although it is logical to express solar production on a daily, weekly or monthly basis, as culture duration can be several weeks or months in practice, fermenter production is most often based on short-term batch culture, typically a few days. We also note that reported productivities only consider production periods, and not process maintenance periods. However, phototrophic and heterotrophic cultures greatly differ in this regard because of the difference in their operation, e.g. the need for stricter cleaning-sterilization protocols for heterotrophic growth, and the difference in culture duration from a few days in batch mode to several weeks or months in semicontinuous solar culture. To conclude, effective productivities on a long-term operation (e.g. a year) for fermentation and solar production processes are difficult to compare. This was also concluded by [54]. We note that the specific growth rate $(\mu)$ is also usually used in fermentation and so could have been taken for comparison. However, as already discussed elsewhere [58], this value is not suitable for phototrophic growth, because of its direct dependence on light attenuation conditions in the culture bulk. For example, a maximum growth rate $\left(\mu_{\max }\right)$ can be easily determined during the fermentation process (the "exponential phase"). However, in phototrophic growth, as the specific growth rate is the average result of local growth rate values determined by the field of light absorption rates (see also Appendix A), such a maximum growth rate, which is higher by definition than an average value, cannot be obtained after light attenuation has appeared. In practice, this is obviously always the case because of the strong absorption capability of microalgal biomass.

Although difficult to compare directly, we note that the AlgoFilm@ PBR presents volumetric productivity in the range of those reported for fermentation. Here we report volumetric productivities of $5.7 \mathrm{~kg} \cdot \mathrm{m}^{-3} \cdot$ day $^{-1}$ and $7.07 \mathrm{~kg} \cdot \mathrm{m}^{-3} \cdot$ day $^{-1}$ in day-night cycles and constant light respectively, with an estimated limit value of $7-8 \mathrm{~kg} \cdot \mathrm{m}^{-3}$. day ${ }^{-1}$ (for Nantes location, France). This is similar to volumetric productivities reported by Behrens [53] after a review of the industrial production of microalgal biomass through fermentation (i.e. $5.8 \mathrm{~kg} \cdot \mathrm{m}^{-3} \cdot \mathrm{day}^{-1}$ ). This highlights the utility of the AlgoFilm@ PBR, which achieved similar performance but in photoautotrophic conditions. The use of light obviously clearly induces specific constraints, e.g. a strong dependence on irradiation conditions, or a scaling-up of culture processes by surface area rather than volume. Photoautotrophic growth has however advantages in terms of (i) metabolites to be produced such as pigments (heterotrophic growth leads to a significant pigment decrease), and (ii) sustainable production (fermentation requires $2-3 \mathrm{~kg}$ of sugar such as glucose per $\mathrm{kg}$ of microalgal biomass) and (iii) operation. The AlgoFilm( $\mathrm{PBR}$, like other microalgal culture systems, can indeed be run easily in continuous or semi-continuous mode, which is not straightforward for fermentation because of axenic issues.

More generally speaking, the high volumetric productivity obtained in the AlgoFilm@ PBR also illustrates that with an appropriate intensification approach, a significant improvement in PBR performance can be

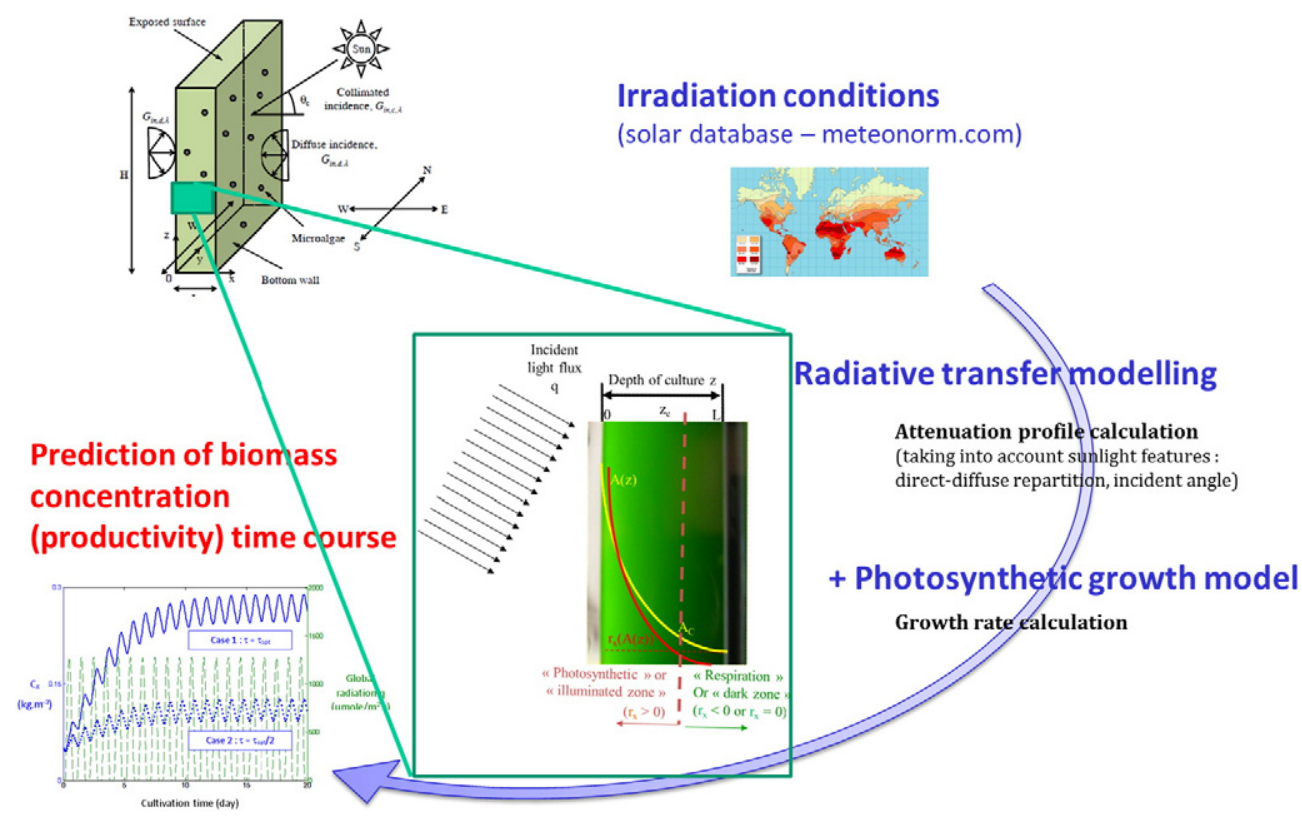

Fig. A1. Overview of the general modeling approach used to simulate solar PBR (for details, see [7,12,59]). 
Table A1

Summary of the growth model parameters for Chlorella vulgaris.

\begin{tabular}{lll}
\hline Parameter & Value & Unit \\
\hline$\rho_{M}$ & 0.82 & - \\
$J_{N_{A D H}}$ & $14 \times 10^{-3}$ & mol $_{\mathrm{NADH}_{2}} \mathrm{~kg}_{\mathrm{x}}^{-1} \mathrm{~s}^{-1}$ \\
$v_{\mathrm{O}_{2} X}$ & 1.13 & - \\
$\bar{\phi}^{\prime}$ & $1.1 \times 10^{-7}$ & $\mathrm{~mol}_{\mathrm{O} 2 \cdot \mu \mathrm{mol}_{\mathrm{hv}}{ }^{-1}}$ \\
$M_{X}$ & 0.024 & $\mathrm{~kg}_{\mathrm{x}} \mathrm{C}-\mathrm{mol}^{-1}$ \\
$v_{N A D H_{2-02}}$ & 1.9 & - \\
$K_{\mathrm{A}}$ & 30,000 & $\mu \mathrm{mol}_{\mathrm{hv}} \mathrm{kg}^{-1} \mathrm{~s}^{-1}$ \\
$K_{r}$ & 26 & $\mu \mathrm{mol}_{\mathrm{hv}} \mathrm{kg}^{-1} \mathrm{~s}^{-1}$ \\
\hline
\end{tabular}

reached. In this study, we demonstrated that the design of an intensified PBR geometry for optimal use of light can allow ceiling performance levels to be closely approached, similar to those encountered with the fermentation production of microalgal biomass in terms of volumetric performance.

\section{Conclusions}

This work presents the model-assisted design of an intensified photobioreactor, AlgoFilm@ $\odot$. Our purpose was to produce a device enabling very high volumetric performance. Based on engineering formulas relating operating and engineering parameters for biomass productivity prediction, generic rules of PBR performance intensification were set. These were then applied to the design of a solar culture system, integrating the constraints of such use. This resulted in the setting-up of the AlgoFilm@ PBR, based on the falling-film principle so as to use very thin culture (around $1.5-2 \mathrm{~mm}$ ) and provide a high specific illuminated surface area (around $500 \mathrm{~m}^{2} \cdot \mathrm{m}^{-3}$, corresponding to $2.1 \mathrm{~L}$ per $\mathrm{m}^{2}$ of illuminated surface).

A complete experimental characterization was then carried out to determine the culture depth, and make sure no limitation other than light occurred, a mandatory condition to control the system and ensure high productivities. This especially concerned the adaptation of culture medium for high-biomass concentration, and gas-liquid mass transfer optimization.

AlgoFilm@ PBR performance was then characterized by culture of $C$. vulgaris. Batch, continuous and semi-continuous culture modes were used, and typical irradiation conditions of a year's operation in Nantes (France) were applied using a LED panel to simulate constant, and then fully-controlled day/night cycles. Our results highlight the high performance of the AlgoFilm@ $(\mathrm{PBR}$, with volumetric productivities very close to those expected from the prior theoretical design. The best measured productivity was $5.7 \mathrm{~kg} \cdot \mathrm{m}^{-3} \cdot$ day $^{-1}\left(7.07 \mathrm{~kg} \cdot \mathrm{m}^{-3}\right.$. day $^{-1}$ in constant light). This value was significantly higher than those reported in the literature, and close to those generally obtained for microalgae production in fermentation processes.

Although already high, these performance levels were still below the maximal performance that could be expected from this technology. A detailed investigation was undertaken, using modeling to gain a deeper insight into the process operation, and especially its transient behavior in day/night cycles. This work evidenced a broad variation in the specific rate of photon absorption in summer, which could negatively impact biological conversion through transient oversaturation of photosynthetic apparatus. These variations were found to be fully dependent on light attenuation conditions in the culture volume. With a better control of these conditions, performance could be further improved, up to a limit value estimated at $7-8 \mathrm{~kg} \cdot \mathrm{m}^{-3} \cdot \mathrm{day}^{-1}$ (for Nantes location, France). However, this calls for a more thorough investigation of the photosynthetic response of a highly intensified PBR working in the dynamic conditions of solar use. This will be the subject of future studies, with the final aim of defining advanced control strategies dedicated to PBRs with high volumetric productivities, such as the AlgoFilm@ PBR. These strategies will be transposed to a scaled-up version of the AlgoFilm@
PBR for outdoor culture $\left(100 \mathrm{~m}^{2}\right)$ that is currently under construction in our facility (AlgoSolis R\&D facility).

\section{Acknowledgments}

This work was supported by the French National Research Agency for bioenergy production (ANR-07-BIOE-007), and is part of the French "BIOSOLIS" research program on developing photobioreactor technologies for mass-scale solar production (http://www.biosolis.org/).

\section{Appendix A. Description of the PBR model}

\section{A.1. Introduction}

Modeling can be used to simulate PBR operation under outdoor solar irradiation [7,59-63]. This approach provides valuable information, by relating engineering parameters and operating conditions (i.e. sunlight conditions) to complex phenomena involved in the process, and in particular the coupling between light transfer in the culture and photosynthetic growth, as illustrated in Fig. A1. This allows the prediction of productivities for PBRs run for a whole year, and also the assessment of the influence of various parameters such as PBR geometry and location, harvesting strategy, strains cultivated, and the effects of night and day cycles. The interested reader can refer to [59] for a complete description of the solar PBR model and to $[7,12,59]$ for more detailed studies. As already described elsewhere, this Appendix summarizes the main features of such a model, and its application for the AlgoFilm() PBR. It follows the same approach recently applied to simulate PBR integration in building façades [64], highlighting the general applicability and robustness of this knowledge model.

\section{A.2. Model description}

As discussed in the main body of this article, culture conditions were defined to obtain the "light-limited" regime, where only light limits growth. This makes process productivity solely dependent on light capture and use in the culture bulk, which have to be modeled and related to obtain the final integrated model (see Fig. A1).

In our case, light attenuation in the culture volume was modeled using the two-flux radiative model. In our study, because we used a LED panel to simulate day-night cycles, normal incidence and collimated radiation could be assumed. Irradiance field was then given by:

$\frac{G}{q}=\frac{(1+\alpha) \exp [-\delta(z-L)]-(1-\alpha) \exp [\delta(z-L)]}{(1+\alpha)^{2} \exp [\delta L]-(1-\alpha)^{2} \exp [-\delta L]}$

In these equations, $\alpha=\sqrt{\frac{E_{a}}{\left(E_{a}+2 b E_{s}\right)}}$ is the linear scattering modulus, and $\delta=\alpha C_{X}\left(E_{\mathrm{a}}+2 b E_{\mathrm{s}}\right)$ is the two-flux extinction coefficient. These values are obtained from radiative properties of the cultivated cells, namely $E_{\mathrm{a}}, E_{\mathrm{s}}$ and $b$, which are respectively the mass absorption coefficient, the mass scattering coefficient, and the back-scattered fraction. These radiative properties are a function of pigment content, as discussed in [16]. The determination of the irradiance field enabled us to calculate light absorbed by biomass as represented by the specific rate of photon absorption $\mathrm{A}$, which is the combination of light received (irradiance $G$ ) and ability of the cells to absorb light (absorption coefficient $\left.E_{\mathrm{a}}\right)$ :

$$
\mathrm{A}=E_{a} G
$$

Determining light absorption rates makes it possible to determine the corresponding photosynthetic growth rate in the culture volume. 
The following kinetic relation already used for C. vulgaris in $[16,64]$ was used:

$$
\begin{aligned}
J_{O_{2}} & =\left[\rho{\overline{\phi^{\prime}}}_{O_{2}} \mathrm{~A}-\frac{J_{\mathrm{NADH}_{2}}}{v_{\mathrm{NADH}_{2}-\mathrm{O}_{2}}} \times \frac{K_{r}}{K_{r}+\mathrm{A}}\right] \\
& =\left[\rho_{\mathrm{M}} \frac{K_{\mathrm{A}}}{K_{\mathrm{A}}+\mathrm{A}} \overline{\phi^{\prime}}{ }_{\mathrm{O}_{2}} \mathrm{~A}-\frac{J_{\mathrm{NADH}_{2}}}{v_{\mathrm{NADH}_{2}-\mathrm{O}_{2}}} \times \frac{K_{r}}{K_{r}+\mathrm{A}}\right]
\end{aligned}
$$

where $\rho=\rho_{M} \frac{K_{A}}{K_{A}+\mathcal{A}}$ is the energy yield for photon conversion of maximum value $\rho_{\mathrm{M}}$ (demonstrated as roughly equal to 0.8 , Table 1$), \overline{\phi^{\prime}}{ }_{\mathrm{O}_{2}}$ is the molar quantum yield for the $Z$-scheme of photosynthesis as deduced from the structured stoichiometric equations, $K_{A}$ is the half saturation constant for photosynthesis, $J_{\mathrm{NADH}_{2}}$ is specific rate of cofactor regeneration on the respiratory chain, here linked to oxygen consumption by the stoichiometric coefficient $v_{\mathrm{NADH}_{2}-\mathrm{O}_{2}}$ (the stoichiometric coefficient of cofactor regeneration on the respiratory chain), $K_{\mathrm{r}}$ is the half saturation constant describing the inhibition of respiration in light.

As a direct result of the light distribution inside the culture, the kinetic relation (Eq. (A3)) is of the local type. This implies calculating the corresponding mean value by averaging over the total culture volume $V_{\mathrm{R}}$ :

$\left\langle J_{O_{2}}\right\rangle=\frac{1}{V_{R}} \iiint_{V_{R}} J_{O_{2}} d V$

Once $\left\langle\mathrm{O}_{2}\right\rangle$ is known, the mean volumetric biomass growth rate $\left\langle r_{X}\right\rangle$ can be deduced directly as:

$\left\langle r_{X}\right\rangle=\frac{\left\langle J_{O_{2}}\right\rangle C_{X} M_{X}}{v_{O_{2}-X}}$

where $M_{X}$ is C-molar mass of the biomass and $v_{O_{2}-X}$ is the stoichiometric coefficient of oxygen production.

The determination of the mean growth rate allows the mass balance equation, here for biomass, to be solved $[59,65,66]$. For a continuous system, assuming perfectly mixed conditions, this equation is:

$\frac{\mathrm{d} C_{X}}{\mathrm{~d} t}=\left\langle r_{X}\right\rangle-\frac{C_{X}}{\tau_{p}}$,

where $\tau_{\mathrm{p}}$ is the residence time resulting from the liquid flow rate of the feed and harvesting strategy.

If the culture system is run in continuous mode with constant light, a steady-state can be achieved $\left(\frac{\mathrm{d} C_{X}}{\mathrm{~d} t}=0\right.$ and then $\left\langle r_{X}\right\rangle=\frac{C_{X}}{\tau_{\mathrm{p}}}$ ). However, in the case of variable PFD as in sunlight conditions, the irradiance field inside the culture bulk and the resulting local and mean volumetric growth rates vary continuously, and so steady-state cannot be assumed in Eq. (A6). This implies solving the transient form of the mass balance equation (using for example the ode23tb routine in Matlab software). If same day-night cycles are reproduced over time, a periodic regime is then achieved (i.e. same daytime course of biomass concentration over a $24 \mathrm{~h}$ period). Only such results are presented in this study (application of reproducible day-night cycles from a LED panel).

Finally, after determining the time course of biomass concentration, we can now calculate the corresponding biomass productivity $\left(P_{v}=\frac{C_{X}}{\tau_{\mathrm{p}}}\right)$.

\section{A.3. Adaptation of the model to the AlgoFilm(C PBR}

Because light attenuation (Eq. (A1)) and related growth rates (Eq. (A3)) are a function of culture depth, it was found necessary to divide the overall volume $V_{R}$ of the AlgoFilm@ PBR into different subvolumes. Three different sub-volumes were considered: the inclined plane (i.e. noted $i p$ ), the transparent tube (i.e. noted $t t$ ), and the remaining culture volume including collector, distributor and pump (i.e. noted $r p$ ). In the conditions investigated, the total culture volume $V_{R}$ was
$0.625 \mathrm{~L}$, distributed as follows $V_{\mathrm{ip}}=0.45 \mathrm{~L}, V_{\mathrm{tt}}=0.035 \mathrm{~L}$ and $V_{\mathrm{rp}}=$ $0.14 \mathrm{~L}$.

The volumetric biomass growth rate $\left\langle r_{X}^{-}\right\rangle$on the overall culture volume was then obtained from Eq. (A7) and used in Eq. (A6) for biomass concentration prediction:

$\left\langle r_{X}\right\rangle=\left\langle r_{X}\right\rangle_{V_{R}}=\frac{V_{i p}\left\langle r_{X}\right\rangle_{i p}+V_{t t}\left\langle r_{X}\right\rangle_{t t}+V_{r p}\left\langle r_{X}\right\rangle_{r p}}{V_{R}}$

For illuminated volume (i.e. inclined surface and transparent tube), volumetric biomass growth rates for each sub-volume were obtained from the light-limited growth model described in the previous section, by considering in Eq. (A1) corresponding average culture depths ( $0.0015 \mathrm{~m}$ and $0.004 \mathrm{~m}$ for inclined plane and transparent tube respectively). We note that transparent tube was considered here as a slab of equivalent depth, so as to avoid having to make a complex numerical resolution of radiative transfer in cylindrical geometries (as described in [18]). Given the small volume of the transparent tube (5\% of the total volume), the influence of this assumption was found to be negligible.

Finally, because the AlgoFilm@ PBR presented a non-illuminated part $\left(V_{\mathrm{rp}}=0.14 \mathrm{~L}\right.$, leading to a design dark fraction $f_{\mathrm{d}}$ of around $22 \%$ ), it was necessary to add a catabolism activity as encountered when microalgae are unlit $\left(\mu_{\mathrm{dark}}=\left\langle r_{X}\right\rangle_{\mathrm{rp}} / C_{X}=0.02 \mathrm{~h}^{-1}\right)$.

All the parameters used in our work are given in Table A1 and are derived from [16] and [64]. All radiative properties $\left(E_{\mathrm{a}}, E_{\mathrm{s}}, b\right)$ of $C$. vulgaris were spectrally averaged over the PAR and the complete database for various pigment contents can be found in supplementary materials in [16]. They were used to simulate photoacclimation by applying the following empirical equations, obtained for $C$. vulgaris following the same procedure described in [41]:

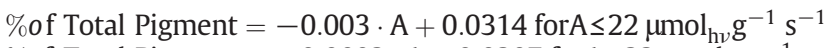
\%of Total Pigment $=-0.0002 \cdot \mathrm{A}+0.0207$ forA $>22 \mu \mathrm{mol}_{\mathrm{h \nu}} \mathrm{g}^{-1} \mathrm{~s}^{-1}$

In Eqs. (1)-(3), the constant $K$ was deduced from Table A1, using $K=K_{A} E a$ (these engineering formulas used irradiance $G$ as a reference value, whereas the growth model is based on the specific rate of photon absorption A, see Eq. (A2)).

\section{References}

[1] A.P. Carvalho, L.A. Meireles, F.X. Malcata, Microalgal reactors: a review of enclosed system designs and performances, Biotechnol. Prog. 22 (2006) 1490-1506.

[2] M. Morweiser, O. Kruse, B. Hankamer, C. Posten, Developments and perspectives of photobioreactors for biofuel production, Appl. Microbiol. Biotechnol. 87 (2010) 1291-1301.

[3] J. Pruvost, Cultivation of algae in photobioreactors for biodiesel production, in: C. Larroche, S.C. Ricke, C.G. Dussap (Eds.),E.I. USA (Ed.) Biofuels: Alternative Feedstocks and Conversion Processes, a Pandey 2011, pp. 439-464.

[4] C.U. Ugwu, H. Aoyagia, H. Uchiyamaa, Photobioreactors for mass cultivation of algae, Bioresour. Technol. 99 (2008) 4021-4028.

[5] J. Pruvost, F. Le Borgne, A. Artu, J.-F. Cornet, J. Legrand, Industrial Photobioreactors and Scale-up Concepts, Advances in Chemical Engineering - Photobioreaction Engineering, Elsevier, 2016 257-310

[6] A. Richmond, Handbook of Microalgal Culture: Biotechnology and Applied Phycology, Blackwell Sciences Ltd, Oxford, UK, 2004.

[7] J. Pruvost, J.F. Cornet, Knowledge models for engineering and optimization of photobioreactors, in: C.P.a.C. Walter (Ed.), Microalgal Biotechnology, KG2012, De Gruyter GmbH \& Co. 2012, pp. 181-224.

[8] J. Doucha, K. Livansky, Productivity, $\mathrm{CO} 2 / \mathrm{O} 2$ exchange and hydraulics in outdoor open high density microalgal (Chlorella sp.) photobioreactorsoperated in a Middle and Southern European climate, J. Appl. Phycol. 18 (2006) 811-826.

[9] J. Pruvost, J.F. Cornet, L. Pilon, Large scale production of algal biomass: photobioreactors, in: U. Springer (Ed.), Algae Biotechnology: Products and Processes 2016, pp. 41-66.

[10] H. Takache, G. Christophe, J.F. Cornet, J. Pruvost, Experimental and theoretical assessment of maximum productivities for the microalgae Chlamydomonas reinhardtii in two different geometries of photobioreactors, Biotechnol. Prog. 26 (2010) 431-440.

[11] J. Pruvost, G. Van Vooren, B. Le Gouic, A. Couzinet-Mossion, J. Legrand, Systematic investigation of biomass and lipid productivity by microalgae in photobioreactors for biodiesel application, Bioresour. Technol. 102 (2011) 150-158. 
[12] J. Pruvost, J.F. Cornet, V. Goetz, J. Legrand, Theoretical investigation of biomass productivities achievable in solar rectangular photobioreactors for the cyanobacterium Arthrospira platensis, Biotechnol. Prog. 28 (2012) 699-714

[13] J.F. Cornet, C.G. Dussap, A simple and reliable formula for assessment of maximum volumetric productivities in photobioreactors, Biotechnol. Prog. 25 (2009) 424-435.

[14] H. Takache G. Christophe, J.F. Cornet, J. Pruvost, Experimental and theoretical assessment of maximum productivities for the micro-algae Chlamydomonas reinhardtii in two different geometries of photobioreactors, Biotechnol. Prog. 26 (2010) 431-440.

[15] J.-F. Cornet, Calculation of optimal design and ideal productivities of volumetrically lightened photobioreactors using the constructal approach, Chem. Eng. Sci. 65 (2010) 985-998.

[16] A. Soulies, C. Castelain, T.I. Burghelea, J. Legrand, H. Marec, J. Pruvost, Investigation and modeling of the effects of light spectrum and incident angle on the growth of Chlorella vulgaris in photobioreactors, Biotechnol. Prog. 32 (2016) 247-261.

[17] J.F. Cornet, Calculation of optimal design and ideal productivities of volumetricallylightened photobioreactors using the constructal approach, Chem. Eng. Sci. 65 (2010) 985-998.

[18] E. Lee, J. Pruvost, X. He, R. Munipalli, L. Pilon, Design tool and guidelines for outdoor photobioreactors, Chem. Eng. Sci. 106 (2014) 18-29.

[19] A.P. Carvalho, S.O. Silva, J.M. Baptista, F.X. Malcata, Light requirements in microalga photobioreactors: an overview of biophotonic aspects, Appl. Microbiol. Biotechnol. 89 (2011) 1275-1288.

[20] M.E. Grima, A.F.G. Fernandez, G.F. Camacho, Y. Chisti, Photobioreactors: light regime, mass transfer, and scaleup, J. Biotechnol. 70 (1999) 231-247.

[21] A. Richmond, Principles for attaining maximal microalgal productivity in photobioreactors: an overview, Hydrobiologia 512 (2004) 33-37.

22] R.B. Bird, W.E. Stewart, E.N. Lightfoot, Transport Phenomena, Second edition John Wiley \& Sons, Inc., 2002

[23] G.F. Hewitt, Measurement of Two Phase Flow Parameters, Academics Press, London and New York, 1978.

[24] J.R. Burns, C. Ramshaw, R.J.M. Jachuck, Measurement of liquid film thickness and the determination of spin-up radius on a rotating disc using an electrical resistance technique, Chem. Eng. Sci. 58 (2003) 2245-2253.

[25] E. Chinnov, S. Kharlamov, A. Nazarov, E. Sokolov, D. Markovich, A. Serov, O. Kabov, Integrated measurement of the wave characteristics of heated film of liquid by the capacitance and fluorescence methods, High Temp. 46 (2008) 647-653.

[26] S. Huang, X. Zhang, D. Wang, Z. Lin, Equivalent water layer height (EWLH) measurement by a single-wire capacitance probe in gas-liquid flows, Int. J. Multiphase Flow 34 (2008) 809-818.

[27] T.D. Karapantsios, S.V. Paras, A.J. Karabelas, Statistical characteristics of free falling films at high Reynolds numbers, Int. J. Multiphase Flow 15 (1989) 1-21.

[28] A.A. Mouza, N.A. Vlachos, S.V. Paras, A.J. Karabelas, Measurement of liquid film thickness using a laser light absorption method, Exp. Fluids 4 (2000) 355-359.

[29] S.V. Alekseenko, A.V. Bobylev, A.R. Evseev, V.M. Karsten, D.M. Markovich, B.V. Tarasov, Measurements of the liquid-film thickness by a fiber-optic probe, Instrum. Exp. Tech. 46 (2003) 260-264.

[30] S.V. Alekseenko, D.M. Markovich, A.R. Evseev, A.V. Bobylev, B.V. Tarasov, V.M. Karsten, Experimental investigation of liquid distribution over structured packing, AICHE J. 54 (2008) 1424-1430.

[31] D.V. Zaitsev, O.A. Kabov, A.R. Evseev, Measurement of locally heated liquid film thickness by a double-fiber optical probe, Exp. Fluids 34 (2003) 748-754

[32] V. Lel, F. Al-Sibai, A. Leefken, U. Renz, Local thickness and wave velocity measurement of wavy films with a chromatic confocal imaging method and a fluorescence intensity technique, Exp. Fluids 39 (2005) 856-864.

[33] S.V. Makarytchev, T.A.G. Langrish, R.G.H. Prince, Thickness and velocity of wavy liquid films on rotating conical surfaces, Chem. Eng. Sci. 56 (2001) 77-87.

[34] M. Roustan, Transferts gaz-liquide dans les procédés de traitement des eaux et des effluents gazeux, Lavoisier, 2003.

[35] N. Sueoka, Mitotic replication of deoxyribonucleic acid in Chlamydomonas reinhardi, Proc. Natl. Acad. Sci. 46 (1960) 83-91.

[36] E. Harris, The Chlamydomonas Sourcebook: A Comprehensive Guide to Biology and Laboratory Use, Academic Press, Inc., 1989

[37] F. Hadj-Romdhane, P. Jaouen, J. Pruvost, D. Grizeau, G. Van Vooren, P. Bourseau, Development and validation of a minimal growth medium for recycling Chlorella vulgaris culture, Bioresour. Technol. 123 (2012) 366-374.

[38] J. Pruvost, G. Van Vooren, G. Cogne, J. Legrand, Investigation of biomass and lipids production with Neochloris oleoabundans in photobioreactor, Bioresour. Technol. 100 (2009) 5988-5995.

[39] R.J. Ritchie, Consistent sets of spectrophotometric chlorophyll equations for acetone, methanol and ethanol solvents, Photosynth. Res. 89 (2006) 27-41.

[40] J.D.H. Strickland, T.R. Parsons, A practical handbook of seawater analysis: pigment analysis, Bulletin of Fisheries Research Board of Canada, 167, 1968.
[41] H. Takache, J. Pruvost, J.F. Cornet, Kinetic modeling of the photosynthetic growth of Chlamydomonas reinhardtii in a photobioreactor, Biotechnol. Prog. 28 (2012) 681-692.

[42] K. Loubiere, E. Olivo, G. Bougaran, J. Pruvost, R. Robert, J. Legrand, A new photobioreactor for continuous microalgal production in hatcheries based on external-loop airlift and swirling flow, Biotechnol. Bioeng. 102 (2009) 132-147.

[43] G. Torzillo, A. Sacchi, R. Materassi, Temperature as an important factor affecting productivity and night biomass loss in Spirulina platensis grown outdoors in tubular photobioreactors, Bioresour. Technol. 38 (1991) 95-100.

[44] F.J. Marquez, K. Sasaki, N. Nishio, S. Nagai, Inhibitory effect of oxygen accumulation on the growth of Spirulina platensis, Biotechnol. Lett. 17 (1995) 225-228.

[45] J. Pruvost, J.F. Cornet, F. Le Borgne, V. Goetz, J. Legrand, Theoretical investigation of microalgae culture in the light changing conditions of solar photobioreactor production and comparison with cyanobacteria, Algal Res. 10 (2015) 87-99.

[46] F. Le Borgne, J. Pruvost, Investigation and modeling of biomass decay rate in the dark and its potential influence on net productivity of solar photobioreactors for microalga Chlamydomonas reinhardtii and cyanobacterium Arthrospira platensis, Bioresour. Technol. 138 (2013) 271-276.

[47] M.A. Borowitzka, Commercial production of microalgae: ponds, tanks, and fermenters, Prog. Ind. Microbiol. 35 (1999) 313-321.

[48] J.U. Grobbelaar, Factors governing algal growth in photobioreactors: the "open" versus “closed" debate, J. Appl. Phycol. 21 (2008) 489-492.

[49] S. Hindersin, M. Leupold, M. Kerner, D. Hanelt, Irradiance optimization of outdoor microalgal cultures using solar tracked photobioreactors, Bioprocess Biosyst. Eng. 36 (2013) 345-355.

[50] S. Hindersin, M. Leupold, M. Kerner, D. Hanelt, Key parameters for outdoor biomass production of Scenedesmus obliquus in solar tracked photobioreactors, J. Appl. Phycol. 26 (6) (2014) 2315-2325.

[51] G. Torzillo, P. Accolla, E. Pinzani, J. Masojidek, In situ monitoring of chlorophyll fluorescence to assess the synergistic effect of low temperature and high irradiance stresses in Spirulina cultures grown outdoors in photobioreactors, J. Appl. Phycol. 8 (1996).

[52] R. Kandilian, J. Pruvost, J. Legrand, L. Pilon, Influence of light absorption rate by Nannochloropsis oculata on triglyceride production during nitrogen starvation, Bioresour. Technol. 163 (2014) 308-319.

[53] P.W. Behrens, in: R.A. Andersen (Ed.), Algal Culturing Techniques. Photobioreactors and Fermentors: The Light and Dark Sides of Growing Algae, Academic Press, 2005.

[54] F. Bumbak, S. Cook, V. Zachleder, S. Hauser, K. Kovar, Best practices in heterotrophic high-cell-density microalgal processes: achievements, potential and possible limitations, Appl. Microbiol. Biotechnol. 91 (2011) 31-46.

[55] Z. Wu, X. Shi, Optimization for high-density cultivation of heterotrophic Chlorella based on a hybrid neural network model, Lett Appl. Microbiol. 44 (2007) 13-18.

[56] O.S. Graverholt, N.T. Eriksen, Heterotrophic high-cell-density fed-batch and continuous-flow cultures of Galdieria sulphuraria and production of phycocyanin, Appl. Microbiol. Biotechnol. 77 (2007) 69-75.

[57] H. Xu, X. Miao, Q. Wu, High quality biodiesel production from a microalga Chlorella protothecoides by heterotrophic growth in fermenters, J. Biotechnol. 126 (2006) 499-507.

[58] A. Taleb, J. Pruvost, J. Legrand, H. Marec, B. Le Gouic, B. Mirabella, B. Legeret, S. Bouvet, G. Peltier, Y. Li-Beisson, S. Taha, H. Takache, Development and validation of a screening procedure of microalgae for biodiesel production: application to the genus of marine microalgae Nannochloropsis, Bioresour. Technol. 177 (2015) 224-232.

[59] J. Pruvost, J.F. Cornet, V. Goetz, J. Legrand, Modeling dynamic functioning of rectangular photobioreactors in solar conditions, AICHE J. 57 (2011) 1947-1960.

[60] J. Quinn, L. De Winter, T. Bradley, Microalgae bulk growth model with application to industrial scale systems, Bioresour. Technol. 102 (2011) 5083-5092.

[61] P.M. Slegers, M.B. Lösing, R.H. Wijffels, G. van Straten, A.J.B. van Boxtel, Scenario evaluation of open pond microalgae production, Algal Res. 2 (2013) 358-368.

[62] P.M. Slegers, P.J.M. van Beveren, R.H. Wijffels, G. van Straten, A.J.B. van Boxtel, Scenario analysis of large scale algae production in tubular photobioreactors, Appl. Energy 105 (2013) 395-406.

[63] P.M. Slegers, R.H. Wijffels, G. Van Straten, A.J.B. Van Boxtel, Design scenarios for flat panel photobioreactors, J. Appl. Energy 88 (2011) 3342-3353.

[64] J. Pruvost, B. Le Gouic, O. Lepine, J. Legrand, F. Le Borgne, Microalgae culture in building-integrated photobioreactors: biomass production modelling and energetic analysis, Chem. Eng. J. 284 (2016) 850-861.

[65] J.F. Cornet, L. Favier, C.G. Dussap, Modeling stability of photoheterotrophic continuous cultures in photobioreactors, Biotechnol. Prog. 19 (2003) 1216-1227.

[66] J. Pruvost, J.F. Cornet, J. Legrand, Hydrodynamics influence on light conversion in photobioreactors: an energetically consistent analysis, Chem. Eng. Sci. 63 (2008) 3679-3694. 